\title{
Optimized Precursor to Simplify Assignment Transfer between Backbone Resonances and Stereospecifically labelled Valine and Leucine Methyl Groups: Application to Human Hsp90 N-Terminal Domain
}

\begin{abstract}
Faustine Henot ${ }^{1}$, Rime Kerfah ${ }^{2}$, Ricarda Törner ${ }^{1}$, Pavel Macek ${ }^{1,2}$, Elodie Crublet ${ }^{2}$, Pierre
\end{abstract} \\ Gans ${ }^{1}$, Matthias Frech ${ }^{3}$, Olivier Hamelin ${ }^{4}$, Jerome Boisbouvier ${ }^{1, *}$ \\ 1. Univ. Grenoble Alpes, CNRS, CEA, Institut de Biologie Structurale (IBS), \\ 71, avenue des martyrs, F-38044 Grenoble, France. \\ 2. NMR-Bio, 5 place Robert Schuman, F-38025 Grenoble, France. \\ 3. Discovery Technologies, Merck KGaA, Frankfurter Straße 250, 64293 Darmstadt, Germany. \\ 4. Univ. Grenoble Alpes, CEA, CNRS, IRIG, CBM-F-38000 Grenoble. France. \\ * correspondence to be addressed to: jerome.boisbouvier@ibs.fr
}

\begin{abstract}
:
Methyl moieties are highly valuable probes for quantitative NMR studies of large proteins. Hence, their assignment is of the utmost interest to obtain information on both interactions and dynamics of proteins in solution. Here, we present the synthesis of a new precursor that allows connection of leucine and valine pro- $S$ methyl moieties to backbone atoms by linear ${ }^{13} \mathrm{C}$-chains. This optimized ${ }^{2} \mathrm{H} /{ }^{13} \mathrm{C}$-labelled acetolactate precursor can be combined with existing ${ }^{13} \mathrm{C} /{ }^{2} \mathrm{H}$ alanine and isoleucine precursors in order to directly transfer backbone assignment to the corresponding methyl groups. Using this simple approach leucine and valine pro- $S$ methyl groups can be assigned using a single sample without requiring correction of ${ }^{1} \mathrm{H} /{ }^{2} \mathrm{H}$ isotopic shifts on ${ }^{13} \mathrm{C}$ resonances. The approach was demonstrated on the $\mathrm{N}$-terminal domain of human HSP90, for which complete assignment of Ala- $\beta$, Ile- $\delta_{1}$, Leu- $\delta_{2}$, Met- $\varepsilon$, Thr- $\gamma$ and Val- $\gamma_{2}$ methyl groups was obtained.
\end{abstract}

Keywords: NMR, assignment, methyl groups, acetolactate, HSP90 


\section{Introduction:}

Solution state NMR is the method of choice to characterize proteins at atomic level and to probe their dynamics over a wide range of biologically relevant timescales. However, for a long-time, study of high molecular weight proteins by NMR remained a challenge, notably due to the extensive line broadening of NMR signals in large proteins. Methyl groups have been widely studied and are extremely useful to overcome this issue that has hampered, in the past, quantitative NMR studies on large proteins. Indeed, due to the proton multiplicity and their favorable relaxation properties, methyl groups allow the detection of NMR signals even for large proteins (Tugarinov et al. 2003). Nowadays, methyl groups are important probes to investigate molecular dynamics (Sprangers and Kay 2007) and to provide functional insight (Rosenzweig et al. 2013; Mas et al. 2018) on assemblies weighing up to 1 MDa. Specific labelling of methyl groups on perdeuterated large proteins allows the measurement of longrange distance restraints, up to $12 \AA$. (Sounier et al. 2007; Ayala et al. 2020) and enables, in combination with other structural biology techniques such as SANS/SAXS (Lapinaite et al. 2013) or Cryo-EM (Gauto et al. 2019), to solve the structure of complexes of several hundreds of $\mathrm{kDa}$.

For the past 20 years, a plethora of protocols overexpressing proteins in $\mathrm{M} 9 /{ }^{2} \mathrm{H}_{2} \mathrm{O}$ based E.coli growth medium and leading to specific protonation of methyl groups in perdeuterated proteins without scrambling of protons to other sites have been elaborated. On one hand, the direct incorporation of the methyl labelled amino acid in $\mathrm{M} 9 /{ }^{2} \mathrm{H}_{2} \mathrm{O}$ is employed for the specific labelling of ${ }^{13} \mathrm{C}^{1} \mathrm{H}_{3}$-alanine (Isaacson et al. 2007; Ayala et al. 2009), ${ }^{13} \mathrm{C}^{1} \mathrm{H}_{3}$-methionine (Gelis et al. 2007; Stoffregen et al. 2012) and ${ }^{13} \mathrm{C}^{1} \mathrm{H}_{3}$-threonine (Velyvis et al. 2012; Ayala et al. 2020). On the other hand, as leucine, valine and isoleucine residues are at the end of irreversible metabolic pathways in E.coli, precursors can be incorporated in the growth medium for their cost-effective labelling. The first precursors introduced to label isoleucine or leucine and valine residues were 2-keto acids: $\alpha$-ketobutyrate (Gardner et al. 1997) and $\alpha$-ketoisovalerate (Goto et al. 1999; Hajduk et al. 2000; Gross et al. 2003), respectively. However, $\alpha$-ketoisovalerate used as a precursor for leucine and valine residues is leading to a non-stereospecific labelling of both pro- $S$ and pro- $R{ }^{13} \mathrm{C}^{1} \mathrm{H}_{3}$ groups resulting in overcrowded spectra for high molecular weight proteins, even when both sensitivity and resolution have been improved using a nonstereospecific ${ }^{13} \mathrm{C}^{1} \mathrm{H}_{3} /{ }^{12} \mathrm{C}^{2} \mathrm{H}_{3} \alpha$-ketoisovalerate (Tugarinov and Kay 2004b).

To prevent peak overlaps and to facilitate studies of large molecular weight assemblies, methyl labelled acetolactate has been used as an alternative precursor (Gans et al. 2010). This 
1 latter enables the stereospecific ${ }^{13} \mathrm{C}^{1} \mathrm{H}_{3}$-labelling of valine and leucine methyl groups and 2 therefore halves the number of peaks observed whilst improving by two the sensitivity of the spectrum as compared to labelling at $50 \%$ pro- $S$ and $50 \%$ pro- $R$ methyl moieties using 4 optimized ${ }^{13} \mathrm{C}^{1} \mathrm{H}_{3} /{ }^{12} \mathrm{C}^{2} \mathrm{H}_{3} \quad \alpha$-ketoisovalerate (Tugarinov and Kay 2004b). This interesting precursor also enhances the intensity of NOE cross peaks and increases the distance threshold at which NOE cross peaks can be detected by $20 \%$ (Gans et al. 2010).

However, despite the tremendous progress made in protocols to selectively introduce protonated methyl groups in perdeuterated proteins, sequence specific assignment, essential for analyzing a variety of NMR data, remains an important challenge for large molecular assemblies. Several methods to solve the bottleneck of assignment of large proteins have been developed including parallel mutagenesis strategies (Amero et al. 2011), structure based approaches using the analysis of NOE cross peaks with various programs (Pritišanac et al. 2020), MAP-XSII (Xu and Matthews 2013), FLAMEnGO 2.0 (Chao et al. 2014), MAGMA (Pritišanac et al. 2017), MAGIC (Monneau et al. 2017), MethylFLYA (Pritišanac et al. 2019), MAUS (Nerli et al. 2021) or the "divide-and-conquer" approach (Gelis et al. 2007; Sprangers and Kay 2007) which is based on separation of large proteins into smaller fragments, assigning these and transferring the assignment back to the full-length protein. For proteins of moderate molecular weight or fragments of large assemblies for which backbone assignment is available, it is possible to connect methyl resonances to those of the backbone. This requires a sample with ${ }^{13} \mathrm{C}^{1} \mathrm{H}_{3}$ labelled methyl groups connected to the backbone by a linear ${ }^{13} \mathrm{C}$-chain. With such a sample, transfer from the assigned backbone to the methyl groups can be achieved using either unidirectional transfer from methyl groups to $\mathrm{HN}$ using (HM)CM(CGCBCA)NH experiments (Tugarinov and Kay 2003) or 'out and back' HCC relay triple resonance experiments (Tugarinov and Kay 2003; Ayala et al. 2012; Mas et al. 2013).

A combination of these techniques to assign methyl groups in addition with a stereospecific labelling, enhancing the sensitivity of the spectrum by a factor two and significantly reducing signal overlap, should lead to straightforward leucine and valine methyl group assignment. Labelling schemes, connecting non-stereospecifically both leucine and valine methyl groups (Tugarinov and Kay 2003), or only pro- $R$ methyl moieties (Mas et al. 2013; Kerfah et al. 2015a), to the assigned backbone are already available. However, with such precursors additional samples are required either to stereospecifically assign the methyl group (Tugarinov and Kay 2004a; Gans et al. 2010) or to link the pro- $S$ methyl to the pro- $R$ one (Mas et al. 2013; Kerfah et al. 2015a). Here we introduce the synthesis of a new dissymmetric ${ }^{13} \mathrm{C} /{ }^{2} \mathrm{H}$ - 
1 backbone atoms to the pro- $S$ methyl groups via a linear ${ }^{13} \mathrm{C}$ chain using only one sample. This 2 new labelling scheme has been applied to the N-terminal domain of human HSP90 (HSP903 NTD) and we present here the full assignment of methyl moieties of this protein.

4

5

6

7

8

9

10

11

12

13

14

15

16

17

18

19

20

21

22

23

24

25

26

27

28

29

30

31

32

33

34 


\section{Materials and Methods}

3 Synthesis of 1, 2, 3-[ $\left.{ }^{13} \mathrm{C}_{3}\right]-4,4,4-\left[{ }^{2} \mathrm{H}_{3}\right]$-acetolactate.

a) Synthesis of ethyl 1, 2, 3- $\left[{ }^{13} \mathrm{C}_{3}\right]-3$-oxo-butanoate. A solution of LiHMDS (7.80 g, 46.6 mmoles, 2.1 equiv.) in freshly dried THF $(150 \mathrm{~mL})$ was cooled to $-78^{\circ} \mathrm{C}$ under argon. 1, 2$\left[{ }^{13} \mathrm{C}_{2}\right]$-ethyl acetate $(2.00 \mathrm{~g}, 22.2 \mathrm{mmoles}$, Cambridge Isotope Laboratory, CIL) was added dropwise. The resulting solution was stirred at $-78^{\circ} \mathrm{C}$ for $15 \mathrm{~min}$, then $1-\left[{ }^{13} \mathrm{C}\right]$-acetyl chloride (1.60 mL, 22.2 mmoles, 1 equiv., CIL) was added dropwise. The resulting mixture was stirred at $-78{ }^{\circ} \mathrm{C}$ for additional $30 \mathrm{~min}$ then quenched by addition of a $20 \%$ aqueous solution of ${ }^{1} \mathrm{HCl}$ $(15 \mathrm{~mL})$. After 3 extractions with $\mathrm{Et}_{2} \mathrm{O}$, the organics were combined, washed with saturated $\mathrm{Na}^{1} \mathrm{HCO}_{3}$ solution then dried over $\mathrm{Na}_{2} \mathrm{SO}_{4}$. Concentration under vacuum affords the desired product $(2.88 \mathrm{~g})$ which was used in the next step without further purification).

${ }^{1} \mathrm{HNMR}:\left(\mathrm{C}^{2} \mathrm{HCl}_{3}\right), \delta: 4.21\left(\mathrm{dq}, \mathrm{O}-\mathrm{CH}_{2},{ }^{3} \mathrm{~J}\left({ }^{1} \mathrm{H}_{-}{ }^{1} \mathrm{H}\right)=7.1 \mathrm{~Hz},{ }^{3} \mathrm{~J}\left({ }^{1} \mathrm{H}_{-}{ }^{13} \mathrm{C}\right)=3.2 \mathrm{~Hz}, 2 \mathrm{H}\right) ; 3.46(\mathrm{dt}$, $\left.{ }^{13} \mathrm{C}_{-}{ }^{13} \mathrm{CH}_{2^{-}}{ }^{13} \mathrm{C},{ }^{2} \mathrm{~J}\left({ }^{1} \mathrm{H}_{-}{ }^{13} \mathrm{C}\right)=6.5 \mathrm{~Hz},{ }^{1} \mathrm{~J}\left({ }^{1} \mathrm{H}_{-}{ }^{13} \mathrm{C}\right)=130.1 \mathrm{~Hz}, 2 \mathrm{H}\right) ; 2.28\left(\mathrm{dd}, \mathrm{CH}_{3^{-}}{ }^{13} \mathrm{C}^{3}{ }^{3} \mathrm{~J}\left(\mathrm{H}_{-}{ }^{13} \mathrm{C}\right)\right.$ $\left.\left.=1.4 \mathrm{~Hz},{ }^{2} \mathrm{~J}\left({ }^{1} \mathrm{H}_{-}{ }^{13} \mathrm{C}\right)=6.1 \mathrm{~Hz}, 3 \mathrm{H}\right), 1.30\left(\mathrm{t}, \mathrm{OCH} 2-\mathrm{CH} 3,{ }^{3} \mathrm{~J}^{1} \mathrm{H}_{-}{ }^{1} \mathrm{H}\right)=7.1 \mathrm{~Hz}, 3 \mathrm{H}\right)$.

b) Synthesis of ethyl 1, 2, 3- $\left[{ }^{13} \mathrm{C}_{3}\right]-2-\left[{ }^{13} \mathrm{C}^{1} \mathrm{H}_{3}\right]-3$-oxo-butanoate. ${ }^{13} \mathrm{C}^{1} \mathrm{H}_{3}-\mathrm{I}(752 \mathrm{~mL}, 11.99$ $\mu$ moles, 1.1 equiv, CIL) was slowly added to a solution of ethyl 1, 2, 3-[ $\left.{ }^{13} \mathrm{C}_{3}\right]$-3-oxo butanoate $(1.45 \mathrm{~g}, 10.90$ mmoles $)$ in $\mathrm{EtO}^{1} \mathrm{H}(50 \mathrm{~mL})$ cooled to $0^{\circ} \mathrm{C}$ before addition of $\mathrm{K}_{2} \mathrm{CO}_{3}(1.66 \mathrm{~g}$, 11.99 mmoles, 1.1 equiv.). The resulting suspension was warmed to room temperature then stirred for $18 \mathrm{~h}$. The mixture was concentrated to the fifth before addition of a large volume of $\mathrm{Et}_{2} \mathrm{O}$. Excess of $\mathrm{K}_{2} \mathrm{CO}_{3}$ was filtered off and the filtrate concentrated under vacuum to the fifth before a further addition of $\mathrm{Et}_{2} \mathrm{O}$ and a second filtration. Concentration under vacuum affords the desired product (1.03 g) as a colorless oil which was used in the next step without further purification.

$\left.{ }^{1} \mathrm{H} \mathrm{NMR}:\left(\mathrm{C}^{2} \mathrm{HCl}_{3}\right), \delta: 4.21\left(\mathrm{dq}, \mathrm{O}-\mathrm{CH}_{2},{ }^{3} \mathrm{~J}^{\mathrm{l}} \mathrm{H}_{-}{ }^{1} \mathrm{H}\right)=7.1 \mathrm{~Hz},{ }^{3} \mathrm{~J}\left({ }^{1} \mathrm{H}_{-}{ }^{13} \mathrm{C}\right)=3.0 \mathrm{~Hz}, 2 \mathrm{H}\right) ; 3.50$ $\left(\mathrm{dm},{ }^{13} \mathrm{C}_{-}{ }^{13} \mathrm{CH}_{-}{ }^{13} \mathrm{C},{ }^{1} \mathrm{~J}\left({ }^{1} \mathrm{H}_{-}{ }^{13} \mathrm{C}\right)=129.0 \mathrm{~Hz}, 1 \mathrm{H}\right) ; 2.24\left(\mathrm{dd}, \mathrm{CH}_{3^{-}}{ }^{13} \mathrm{C}^{3}{ }^{3} \mathrm{~J}^{1} \mathrm{H}_{-}{ }^{13} \mathrm{C}\right)=1.3 \mathrm{~Hz},{ }^{2} \mathrm{~J}\left({ }^{1} \mathrm{H}_{-}\right.$ $\left.\left.{ }^{13} \mathrm{C}\right)=6.0 \mathrm{~Hz}, 3 \mathrm{H}\right), 1.36\left(\mathrm{dm},{ }^{13} \mathrm{CH}_{3},{ }^{1} \mathrm{~J}\left(\mathrm{H}_{-}{ }^{13} \mathrm{C}\right)=129.0 \mathrm{~Hz}, 3 \mathrm{H}\right), 1.28\left(\mathrm{t}, \mathrm{OCH}_{2}-\mathrm{CH}_{3},{ }^{3} \mathrm{~J}\left({ }^{1} \mathrm{H}-\right.\right.$ $\left.\left.{ }^{1} \mathrm{H}\right)=7.1 \mathrm{~Hz}, 3 \mathrm{H}\right)$.

c) Synthesis of ethyl $1,2,3-\left[{ }^{13} \mathrm{C}_{3}\right]-2-\left[{ }^{13} \mathrm{C}^{1} \mathrm{H}_{3}\right]-2-\left[\mathrm{O}^{1} \mathrm{H}\right]-3$-oxo-butanoate. To a solution of ethyl 1, 2, 3-[ $\left[{ }^{13} \mathrm{C} 3\right]-2-\left[{ }^{13} \mathrm{C}^{1} \mathrm{H}_{3}\right]$-3-oxo butanoate (995 mg, $\left.6.72 \mathrm{mmoles}\right)$ in DMSO (8 mL), $\mathrm{Cs}_{2} \mathrm{CO}_{3}$ was added (440 mg, 1.35 mmoles, 0.2 equiv.). After $\mathrm{O}_{2}$ bubbling for $15 \mathrm{~min}$., $\mathrm{P}(\mathrm{OEt})_{3}(233 \mathrm{~mL}$, 1.35 mmoles, 0.2 equiv.) was added. The resulting solution was stirred under $\mathrm{O}_{2}$ atmosphere 
1 for $20 \mathrm{~h}$. A large volume of $\mathrm{Et}_{2} \mathrm{O}$ was then added followed by a saturated $\mathrm{NaCl}$ solution. The 2 resulting phases were separated and the aqueous one was extracted one more time with $\mathrm{Et}_{2} \mathrm{O}$.

3 The organics were combined, dried over $\mathrm{Na}_{2} \mathrm{SO}_{4}$ then concentrated under vacuum to obtain ethyl 1, 2, 3- $\left[{ }^{13} \mathrm{C}_{3}\right], 2-\left[{ }^{13} \mathrm{C}^{1} \mathrm{H}_{3}\right], 2-\left[\mathrm{O}^{1} \mathrm{H}\right]-3$-oxobutanoate as a yellow oil $(1.142 \mathrm{~g})$ and pure enough to be used in the next step without further purification.

$\left.\left.{ }^{1} \mathrm{H} N M R:\left(\mathrm{C}^{2} \mathrm{HCl}_{3}\right), \delta: 4.25\left(\mathrm{dq}, \mathrm{O}-\mathrm{CH}_{2},{ }^{3} \mathrm{~J}^{1} \mathrm{H}_{-}{ }^{1} \mathrm{H}\right)=7.1 \mathrm{~Hz},{ }^{3} \mathrm{~J}^{1}{ }^{1} \mathrm{H}_{-}{ }^{13} \mathrm{C}\right)=3.2 \mathrm{~Hz}, 2 \mathrm{H}\right)$; $4.17-$ $4.24(\mathrm{~m}, \mathrm{OH}, \mathrm{lH}), 2.27\left(\mathrm{dd}, \mathrm{CH}_{3^{-}}{ }^{13} \mathrm{C},{ }^{3} \mathrm{~J}^{1}\left(\mathrm{H}_{-}{ }^{13} \mathrm{C}\right)=1.1 \mathrm{~Hz},{ }^{2} \mathrm{~J}^{1}\left(\mathrm{H}_{-}{ }^{13} \mathrm{C}\right)=6.1 \mathrm{~Hz}, 3 \mathrm{H}\right), 1.36(\mathrm{dm}$, $\left.{ }^{13} \mathrm{CH}_{3},{ }^{1} \mathrm{~J}\left(\mathrm{H}_{-}{ }^{13} \mathrm{C}\right)=134.2 \mathrm{~Hz}, 3 \mathrm{H}\right), 1.28\left(\mathrm{t}, \mathrm{OCH} 2-\mathrm{CH} 3,{ }^{3} \mathrm{~J}\left({ }^{1} \mathrm{H}-{ }^{1} \mathrm{H}\right)=7.1 \mathrm{~Hz}, 3 \mathrm{H}\right)$.

d) Synthesis of sodium 1, 2, 3- $\left[{ }^{13} \mathrm{C}_{3}\right]-2-\left[{ }^{13} \mathrm{C}^{1} \mathrm{H}_{3}\right]-2-\left[\mathrm{O}^{2} \mathrm{H}\right]-3-$ oxo-4, 4, 4- $\left[{ }^{2} \mathrm{H}_{3}\right]$-butanoate. To a solution of ethyl 1, 2, 3-[ $\left[{ }^{13} \mathrm{C}_{3}\right]-2-\left[{ }^{13} \mathrm{C}^{1} \mathrm{H}_{3}\right]-2-\left[\mathrm{O}^{1} \mathrm{H}\right]-3$-oxobutanoate $(1.09 \mathrm{~g})$ in ${ }^{2} \mathrm{H}_{2} \mathrm{O}(4 \mathrm{~mL})$, 0.4 equivalents of a solution of $\mathrm{NaO}^{2} \mathrm{H}(2.5 \mathrm{M})$ in ${ }^{2} \mathrm{H}_{2} \mathrm{O}$ were added dropwise in $40 \mathrm{~min}$, using a syringe pump under argon. As soon as the addition was completed, ${ }^{1} \mathrm{H}$ NMR was carried out on a sample (few $\mu \mathrm{L}$ ) in ${ }^{2} \mathrm{H}_{2} \mathrm{O}$ in order to calculate the conversion percentage (ratio between the amount of hydrolyzed product (quadruplet at $1.60 \mathrm{ppm}$ ) and the amount of starting material (quadruplet at $1.7 \mathrm{ppm}$ )). 1.1 equivalent of $\mathrm{NaO}^{2} \mathrm{H}$ solution $(2.5 \mathrm{M})$ was added over $30 \mathrm{~min}$ with the syringe pump. As soon as the addition was completed, an extraction with diethyl ether was carried out in order to remove the by-product coming from the previous step whose NMR signals prevent a good follow-up of the hydrogen/deuterium $\left({ }^{1} \mathrm{H} /{ }^{2} \mathrm{H}\right)$ exchange on the 4- $\mathrm{CH}_{3}$ (2.2 ppm). The ${ }^{1} \mathrm{H} /{ }^{2} \mathrm{H}$ exchange on $4-\mathrm{CH}_{3}$ was then monitored by ${ }^{1} \mathrm{H}$ NMR and carried out by successive addition of $\mathrm{NaO}^{2} \mathrm{H}(2.5 \mathrm{M})$ until the integral of the doublet corresponding to the $\mathrm{CH}_{3}$ reaches the value of 0.1 when the quadruplet at $1.6 \mathrm{ppm}$ integrates for 1.5 . The reaction was immediately neutralized with a concentrated ${ }^{2} \mathrm{HCl}$ solution to neutral $\mathrm{pH}$ and then buffered with Tris- ${ }^{1} \mathrm{HCl},\left(1.0 \mathrm{M}, \mathrm{pH} 7.5\right.$ in $\left.{ }^{2} \mathrm{H}_{2} \mathrm{O}\right)$. The concentration of the resulting solution was then determined by ${ }^{1} \mathrm{H}$ NMR using methanol or acetonitrile as internal reference. The final product (3.02 mmoles) was stored at $-80^{\circ} \mathrm{C}$.

${ }^{1} \mathrm{H} N M R:\left(\mathrm{C}^{2} \mathrm{HCl}_{3}\right), \delta: 1.37\left(\mathrm{dq},{ }^{13} \mathrm{CH}_{3},{ }^{1} \mathrm{~J}\left({ }^{1} \mathrm{H}_{-}{ }^{13} \mathrm{C}\right)=129.3 \mathrm{~Hz},{ }^{2} \mathrm{~J}\left({ }^{1} \mathrm{H}_{-}{ }^{13} \mathrm{C}\right)=3.9 \mathrm{~Hz}, \mathrm{lH}\right)$.

\section{Preparation of isotopically labelled HSP90-NTD samples.}

E. coli BL21-DE3-RIL cells transformed with a pET-28 plasmid encoding the N-Terminal domain of HSP90 $\alpha$ from Homo Sapiens (HSP90-NTD) with a His-Tag and a TEV cleavage site were progressively adapted in three stages over $24 \mathrm{~h}$ to $\mathrm{M} 9 /{ }^{2} \mathrm{H}_{2} \mathrm{O}$. In the final culture, bacteria were grown at $37^{\circ} \mathrm{C}$ in M9 medium with $99.85 \%{ }^{2} \mathrm{H}_{2} \mathrm{O}$ (Eurisotop), $1 \mathrm{~g} / \mathrm{L}^{15} \mathrm{~N}^{1} \mathrm{H}_{4} \mathrm{Cl}$ 
1 (Sigma Aldrich) and $2 \mathrm{~g} / \mathrm{L}$ D-glucose- $\mathrm{d}_{7}$ (for U- $\left[{ }^{2} \mathrm{H},{ }^{12} \mathrm{C},{ }^{15} \mathrm{~N}\right]$ HSP90-NTD samples) or D2 glucose- ${ }^{13} \mathrm{C}_{6}-\mathrm{d}_{7}$ (CIL) (for U- $\left[{ }^{2} \mathrm{H},{ }^{13} \mathrm{C},{ }^{15} \mathrm{~N}\right]$ HSP90-NTD samples).

3 For methyl specifically labelled samples, the methyl labelled precursors or amino-acids were added to the media when the O.D at $600 \mathrm{~nm}$ reached 0.6 (Kerfah et al. 2015c):

- Labelling scheme (A): for production of the $\mathrm{U}-\left[{ }^{2} \mathrm{H},{ }^{15} \mathrm{~N},{ }^{13} \mathrm{C}\right]$, Ile- $\left[2,3,4,4-{ }^{2} \mathrm{H}_{4} ; 1,2\right.$, $\left.\left.3,4-{ }^{13} \mathrm{C}_{4} ;{ }^{13} \mathrm{C}^{1} \mathrm{H}_{3}\right]{ }^{\delta 1} /\left[{ }^{12} \mathrm{C}^{2} \mathrm{H}_{3}\right]{ }^{\gamma 2}\right]$, Leu- $\left[2,3,3,4-{ }^{2} \mathrm{H}_{4} ; 1,2,3,4-{ }^{13} \mathrm{C}_{4} ;\left[{ }^{13} \mathrm{C}^{1} \mathrm{H}_{3}\right]{ }^{\text {pro- }}\right.$ $\left.{ }^{S} /\left[{ }^{12} \mathrm{C}^{2} \mathrm{H}_{3}\right]^{\text {pro- } R}\right]$, Val- $\left[2,3-{ }^{2} \mathrm{H}_{2} ; 1,2,3-{ }^{13} \mathrm{C}_{3} ;\left[{ }^{13} \mathrm{C}^{1} \mathrm{H}_{3}\right]{ }^{\text {pro- } S} /\left[{ }^{12} \mathrm{C}^{2} \mathrm{H}_{3}\right]{ }^{\text {pro- } R}\right]$ HSP90-NTD, a solution containing the sodium $1,2,3-\left[{ }^{13} \mathrm{C}_{3}\right]-2-\left[{ }^{13} \mathrm{C}^{1} \mathrm{H}_{3}\right]-2-\left[\mathrm{O}^{2} \mathrm{H}\right]-3-\mathrm{oxo}-4,4,4-\left[{ }^{2} \mathrm{H}_{3}\right]-$ butanoate precursor was added at a concentration of $172 \mathrm{mg} / \mathrm{L} 1 \mathrm{~h}$ before induction. 40 min later (20 minutes before induction) a solution containing $60 \mathrm{mg} / \mathrm{L}$ of sodium $(S)-2-$ hydroxy-2-(1',1'-[ $\left.\left.{ }^{2} \mathrm{H}_{2}\right], \quad 1^{\prime}, \quad 2^{\prime}-\left[{ }^{13} \mathrm{C}_{2}\right]\right)$ ethyl-3-oxo-1,2,3- $\left[{ }^{13} \mathrm{C}_{3}\right]-4,4,4-\left[{ }^{2} \mathrm{H}_{3}\right]$ butanoate (Kerfah et al. 2015a) was added to the medium.

- Labelling scheme (B): for production of the U- $\left[{ }^{2} \mathrm{H},{ }^{15} \mathrm{~N},{ }^{12} \mathrm{C}\right]$, Ala- $\left[{ }^{13} \mathrm{C}^{1} \mathrm{H}_{3}\right]$, Met$\left[{ }^{13} \mathrm{C}^{1} \mathrm{H}_{3}\right]$, Leu/Val- $\left[{ }^{13} \mathrm{C}^{1} \mathrm{H}_{3}\right]{ }^{\text {pro- } S}$, Ile- $\left[{ }^{13} \mathrm{C}^{1} \mathrm{H}_{3}\right]{ }^{\delta 1}$, Thr- $\left[{ }^{13} \mathrm{C}^{1} \mathrm{H}_{3}\right]{ }^{\gamma}$ HSP90-NTD, a HLAM$\mathrm{A}^{\beta} \mathrm{I}^{\delta 1} \mathrm{M}^{\varepsilon} \mathrm{LV}^{\mathrm{proS}} \mathrm{T}^{\gamma}$ kit, purchased from NMR-Bio, was added before induction according to the manufacturer's protocol.

- Labelling scheme (C): U- $\left[{ }^{2} \mathrm{H},{ }^{15} \mathrm{~N},{ }^{12} \mathrm{C}\right]$ samples labelled on a single type of methyl group were produced in small scales $(21 \mathrm{~mL})$ to identify $\mathrm{A}^{\beta}, \mathrm{M}^{\varepsilon}, \mathrm{T}^{\gamma}$ methyl type (3 samples) or to complete assignment using single point mutants (Amero et al. 2011) (33 samples, list of mutants presented in the legend of Fig. S4). Single point amino acid mutations were generated by GeneCust. For each of these samples a single type of methyl groups was labelled by addition of the corresponding NMR-Bio kit (SLAM-A ${ }^{\beta}$,

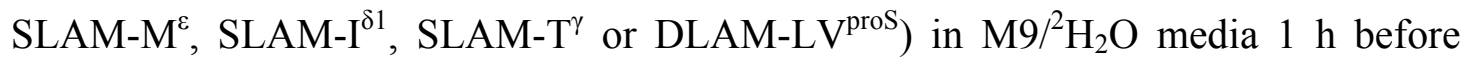
induction.

Protein production was induced by the addition of IPTG to a final concentration of 0.5 $\mathrm{mM}$. The cultures were grown overnight at $20^{\circ} \mathrm{C}$ before harvesting. Cells were collected by centrifugation at $5500 \mathrm{~g}$ for $20 \mathrm{~min}$ at $4^{\circ} \mathrm{C}$ then lysed by sonication on ice in a buffer containing $20 \mathrm{mM}$ phosphate sodium buffer at $\mathrm{pH} 7.4,0.5 \mathrm{M} \mathrm{NaCl}, 0.05 \% \beta$-ME, antiprotease (cOmplete ${ }^{\circledR}$ EDTA free, 1 tablet for $50 \mathrm{~mL}$ ), $50 \mu \mathrm{g} / \mathrm{mL}$ DNAse (Sigma Aldrich), 50 $\mu \mathrm{g} / \mathrm{mL}$ RNAse (Euromedex), and $0.25 \mathrm{mg} / \mathrm{mL}$ Lysozyme (Euromedex). After removal of cell debris by centrifugation $\left(45,000 \times \mathrm{g}, 30 \mathrm{~min}, 4^{\circ} \mathrm{C}\right)$, the supernatant was purified using an affinity chromatography step (Ni-NTA, Superflow, QIAGEN) (labelling scheme A, B and C), followed by a size exclusion chromatography step (16/600 Superdex 75 PG, GE Healthcare) (labelling 
1 schemes A and B only). The gel filtration column was run with an isocratic step of the NMR buffer (20 mM Hepes, $150 \mathrm{mM} \mathrm{NaCl,} 1 \mathrm{mM}$ TCEP, pH 7.5).

The HSP90-NTD proteins were concentrated, using an Amicon® 4 Centrifugal Filter Unit with a 10,000 MWCO (Merck), either in a $90 \% / 10 \%{ }^{1} \mathrm{H}_{2} \mathrm{O} /{ }^{2} \mathrm{H}_{2} \mathrm{O}$ or in a $100 \%{ }^{2} \mathrm{H}_{2} \mathrm{O}$ buffer containing $20 \mathrm{mM}$ Hepes, $150 \mathrm{mM} \mathrm{NaCl}, 1 \mathrm{mM}$ TCEP, pH 7.5. For labelling schemes A and $\mathrm{B}$, samples were concentrated to $0.5 \mathrm{mM}$ and $200 \mu \mathrm{L}$ of each sample was loaded in $4 \mathrm{~mm}$ shigemi tube. The wild type and single point mutants of HSP90-NTD proteins labelled on only one methyl type (labelling scheme $\mathrm{C}$ ) were concentrated at $[0.1-0.4] \mathrm{mM}$ and $40 \mu \mathrm{L}$ of each sample was loaded in a $1.7 \mathrm{~mm}$ NMR tube.

\section{NMR Spectroscopy}

All NMR experiments acquired on HSP90-NTD samples were recorded at 298 K. 2D ${ }^{1} \mathrm{H}-{ }^{13} \mathrm{C}$ SOFAST methyl TROSY (Amero et al. 2009) experiments to identify each methyl type as well as to assign individual methyl signals using single point mutants were recorded for an average duration of $\sim 1.5 \mathrm{~h}$ each, on a spectrometer operating at a ${ }^{1} \mathrm{H}$ frequency of $850 \mathrm{MHz}$ and equipped with a $1.7 \mathrm{~mm}$ cryogenically cooled, pulsed-field-gradient triple-resonance probe. All other NMR experiments were acquired using Bruker Avance III HD spectrometers equipped with $5 \mathrm{~mm}$ cryogenic probes (operating at a ${ }^{1} \mathrm{H}$ frequency of 600 or $950 \mathrm{MHz}$ ).

The 3D HCC, HC(C)C and HC(CC)C experiments (Tugarinov and Kay 2003; Ayala et al. 2009, 2012; Mas et al. 2013) were acquired on a spectrometer operating at a ${ }^{1} \mathrm{H}$ frequency of $600 \mathrm{MHz}$ for a total duration of 4 days, using a $0.5 \mathrm{mM}$ sample of $\mathrm{U}-\left[{ }^{2} \mathrm{H},{ }^{15} \mathrm{~N},{ }^{13} \mathrm{C}\right]$, Ile- $[2$, $\left.\left.3,4,4-{ }^{2} \mathrm{H}_{4} ; 1,2,3,4-{ }^{13} \mathrm{C}_{4} ;{ }^{13} \mathrm{C}^{1} \mathrm{H}_{3}\right]{ }^{\delta 1} /\left[{ }^{12} \mathrm{C}^{2} \mathrm{H}_{3}\right]{ }^{\gamma 2}\right]$, Leu- $\left[2,3,3,4-{ }^{2} \mathrm{H}_{4} ; 1,2,3,4-{ }^{13} \mathrm{C}_{4} ;\left[{ }^{13} \mathrm{C}^{1} \mathrm{H}_{3}\right]{ }^{\text {pro- }}\right.$ $\left.S /\left[{ }^{12} \mathrm{C}^{2} \mathrm{H}_{3}\right]{ }^{\text {pro- } R}\right]$, Val- $\left.\left[2,3-{ }^{2} \mathrm{H}_{2} ; 1,2,3-{ }^{13} \mathrm{C}_{3} ;\left[{ }^{13} \mathrm{C}^{1} \mathrm{H}_{3}\right]\right]^{\text {pro- } S} /\left[{ }^{12} \mathrm{C}^{2} \mathrm{H}_{3}\right]{ }^{\text {pro- } R}\right]$ HSP90-NTD. The interscan delay was adjusted to $0.5-0.6 \mathrm{~s}$, the heteronuclear ${ }^{1} \mathrm{H}->{ }^{13} \mathrm{C}$ transfer delay was set to $4 \mathrm{~ms}\left(1 /\left(2 \times{ }^{1} \mathrm{~J}_{\mathrm{HC}}\right)\right)$ and the homonuclear ${ }^{13} \mathrm{C}->{ }^{13} \mathrm{C}$ transfer delay was fixed to $12.5 \mathrm{~ms}$. The acquisition times were adjusted to $8-10.7 \mathrm{~ms}$ in the ${ }^{13} \mathrm{C}$ indirect dimension, and to $70 \mathrm{~ms}$ in ${ }^{1} \mathrm{H}$ direct dimension.

For the sequential assignment of backbone resonances, a set of 6 BEST-TROSY 3D triple resonance experiments $(\mathrm{HNCA}, \mathrm{HN}(\mathrm{CA}) \mathrm{CB}, \mathrm{HNCO}, \mathrm{HN}(\mathrm{CA}) \mathrm{CO}, \mathrm{HN}(\mathrm{CO}) \mathrm{CA}$ and $\mathrm{HN}(\mathrm{COCA}) \mathrm{CB}$ (Favier and Brutscher 2019) were acquired on a Bruker Avance III HD spectrometer equipped with a cryogenic probe and operating at a ${ }^{1} \mathrm{H}$ frequency of $600 \mathrm{MHz}$ for a total duration of 11 days using a $0.5 \mathrm{mM}$ sample of the $\mathrm{U}-\left[{ }^{2} \mathrm{H},{ }^{15} \mathrm{~N},{ }^{13} \mathrm{C}\right] \mathrm{HSP} 90-\mathrm{NTD}$.

The 3D CCH HMQC-NOESY-HMQC NMR experiment (Tugarinov et al. 2005; Törner et al. 2020) was recorded over 3 days on a spectrometer operating at a ${ }^{1} \mathrm{H}$ frequency of $950 \mathrm{MHz}$ 
1 using a $0.5 \mathrm{mM}$ sample of $\mathrm{U}-\left[{ }^{2} \mathrm{H},{ }^{15} \mathrm{~N},{ }^{12} \mathrm{C}\right]$, Ala- $\left[{ }^{13} \mathrm{C}^{1} \mathrm{H}_{3}\right]{ }^{\beta}$, Met- $\left[{ }^{13} \mathrm{C}^{1} \mathrm{H}_{3}\right]$, Leu/Val- $\left.\left[{ }^{13} \mathrm{C}^{1} \mathrm{H}_{3}\right]\right]^{\text {pro- }}$ $2 \stackrel{S}{ }$, Ile- $\left[{ }^{13} \mathrm{C}^{1} \mathrm{H}_{3}\right]^{\delta 1}$, Thr- $\left[{ }^{13} \mathrm{C}^{1} \mathrm{H}_{3}\right]^{\gamma}$ HSP90-NTD. The interscan delay was set to $1.1 \mathrm{~s}$. The 3 heteronuclear ${ }^{1} \mathrm{H}->{ }^{13} \mathrm{C}$ transfer delay was set to $4 \mathrm{~ms}\left(1 /\left(2 \mathrm{x}^{1} \mathrm{~J}_{\mathrm{HC}}\right)\right)$. The acquisition times in 4 the ${ }^{13} \mathrm{C}$ indirect dimension were set to $24.6 \mathrm{~ms}$, $\left(\mathrm{t}_{1 \max }\right)$ and to $18.6 \mathrm{~ms}\left(\mathrm{t}_{2 \max }\right)$. In the ${ }^{1} \mathrm{H}$ direct 5 dimension $t_{3 \max }$ was fixed to $80 \mathrm{~ms}$. The NOE mixing period was set to $500 \mathrm{~ms}$ to detect a 6 maximum number of long-range intermethyl NOEs.

\section{Data processing and analysis}

All data were processed and analyzed using nmrPipe/nmrDraw (Delaglio et al. 1995) and CcpNMR (Vranken et al. 2005). Automated methyl assignment was performed using MAGIC software (Monneau et al. 2017) using the reference structure of HSP90-NTD (PDB: 1YES). Input NOE lists for MAGIC were created with CcpNMR. MAGIC was run with a score threshold factor of 1 and distance thresholds of 7-10 $\AA$ using all inter methyl NOEs detected ( $\mathrm{S} / \mathrm{N}$ threshold of 5 was used) and given the assignment of isoleucines, leucines and valines previously obtained by the three 'out and back' HCC experiments as well as alanine, methionine and threonine methyl groups assigned by mutagenesis as additional input. 


\section{Results and Discussion}

To assign methyl groups of large perdeuterated proteins, previously assigned backbone resonances of these proteins can be used (Tugarinov and Kay 2003; Ayala et al. 2012; Mas et al. 2013). Nonetheless, to do so, methyl groups need to be connected, via a linear chain of ${ }^{13} \mathrm{C}$, to the backbone atoms in order to be able to apply optimized experiments to high molecular weight proteins. Strategies to label stereospecifically leucine and valine pro- $R$ methyl groups and to connect them to backbone nuclei have already been proposed (Mas et al. 2013). However, it has to be noted that pro- $S$ methyl groups are often chosen over pro- $R$ methyl groups as they are both easier and cheaper to label stereospecifically (Gans et al. 2010). In order to simplify assignment of pro- $S$ methyl groups using already assigned backbone resonances and to avoid the need of an additional sample to link the pro- $S$ methyl to the pro- $R$ one, a sample connecting the pro- $S{ }^{13} \mathrm{C}^{1} \mathrm{H}_{3}$-methyl groups to the backbone atoms by a linear ${ }^{13} \mathrm{C}$-chain and labelled with ${ }^{12} \mathrm{C}^{2} \mathrm{H}_{3}$ on pro- $R$ methyl moieties to avoid signal loss would be optimal.

\section{Synthesis of optimally labelled acetolactate precursors and proteins.}

Taking into account the specificity of leucine/valine metabolic pathway in E. coli, such an optimal labelling scheme can be achieved in $\mathrm{M} 9 /{ }^{2} \mathrm{H}_{2} \mathrm{O}$ medium using ${ }^{13} \mathrm{C} /{ }^{2} \mathrm{H}$ glucose (Kerfah et al. 2015c) as a carbon source together with 1, 2, 3- $\left[{ }^{13} \mathrm{C}_{3}\right]-2-\left[{ }^{13} \mathrm{C}^{1} \mathrm{H}_{3}\right]-2-\left[\mathrm{O}^{2} \mathrm{H}\right]-3-\mathrm{oxo}-4,4,4-$ $\left[{ }^{2} \mathrm{H}_{3}\right]$-butanoate as suitably labelled acetolactate precursor. However, this latter cannot be synthetized from commercially available materials by the traditional route starting from acetoacetate (Gans et al. 2010) since the corresponding labelled starting material is not commercially available. Indeed, acetolactate chemical synthesis is achieved by reaction of iodomethane on acetoacetate (Gans et al. 2010). Whilst both ${ }^{13} \mathrm{C}^{1} \mathrm{H}_{3}$ labelling of the methyl substituent in position 2 and deuteration of the methyl group in position 4 can be obtained using ${ }^{13} \mathrm{C}^{1} \mathrm{H}_{3} \mathrm{I}$ as a starting synthesis material and hydrogen/deuterium exchange in controlled basic conditions (Gans et al. 2010), respectively, the ${ }^{13} \mathrm{C}$ labelling of only the first three carbons of the main chain using commercially available labelled acetoacetate materials is not achievable. Therefore, as acetoacetate can be obtained by condensation of two acetate moieties (Epstein J et al. 1977), we decided to set up a synthesis of dissymmetrically labelled acetoacetate starting from commercially available ethyl $1,2-\left[{ }^{13} \mathrm{C}_{2}\right]$ - acetate with $1-\left[{ }^{13} \mathrm{C}\right]$-acetyl chloride. Based on reported procedures, we established a 4-step synthesis (Fig. 1) allowing to prepare the desired precursor with an overall yield of $27 \%$. In brief, the dissymmetry is achieved by the Claisen condensation of ethyl-1,2, $\left[{ }^{13} \mathrm{C}_{2}\right]$-acetate with $1-\left[{ }^{13} \mathrm{C}\right]$-acetyl chloride using an optimization of a 
1 reported procedure (Epstein $\mathrm{J}$ et al. 1977) (a), followed by an alkylation in position 2 using $2{ }^{13} \mathrm{C}^{1} \mathrm{H}_{3} \mathrm{I}(\mathrm{b})$ and a subsequent hydroxylation in position 2 (c). Finally, the last step combining both saponification of the ester and a hydrogen/deuterium exchange in position 4 is performed under controlled basic conditions (d). This last step is very delicate and requires a fine control of the basic condition as a methyl rearrangement above a $\mathrm{pH}$ of 13.5 can take place resulting in the interconversion of both methyl groups (Gans et al. 2010). Steps (b) and (c) are not stereoselective, hence, products of these latter steps were produced as racemic mixtures. The optimally labelled acetolactate, unstable at room temperature, was aliquoted and stored at $80^{\circ} \mathrm{C}$

The synthetized acetolactate precursor was incorporated in E. coli. $\mathrm{M} 9 /{ }^{2} \mathrm{H}_{2} \mathrm{O}$ culture media without any further purification steps to label the overexpressed protein. Frozen acetolactate vials were thawed right before addition in the culture medium to avoid degradation or methyl rearrangement. It has to be noted that only the $2-(S)$ stereoisomer of acetolactate is converted in vivo by ketol-acid reductoisomerase (EC1.1.1.86) and dihydroxyacid dehydratase (EC 4.2.1.9) to form the stereospecifically labelled 2-keto-isovalerate. This latter is afterwards directly converted into valine or combined with ${ }^{13} \mathrm{C} /{ }^{2} \mathrm{H}$-pyruvate, derived from the ${ }^{13} \mathrm{C} /{ }^{2} \mathrm{H}$ glucose, to produce leucine with the desired labelling pattern. The 2-(R) stereoisomer of acetolactate is, itself, not a substrate of ketol-acid reductoisomerase and hence, induces no scrambling (Gans et al. 2010). The synthetized 1, 2, 3-[ $\left[{ }^{13} \mathrm{C}_{3}\right]-2-\left[{ }^{13} \mathrm{C}^{1} \mathrm{H}_{3}\right]-2-\left[\mathrm{O}^{2} \mathrm{H}\right]-3$-oxo-4, 4, 4$\left[{ }^{2} \mathrm{H}_{3}\right]$-butanoate can be mixed with other known precursors allowing also to connect methyl groups, such as Ile- $\delta_{1}$ (Kerfah et al. 2015b, a; Törner et al. 2020), Ile- $\gamma_{2}$ (Ayala et al. 2012) or Ala- $\beta$ (Ayala et al. 2009; Kerfah et al. 2015a; Törner et al. 2020), to backbone nuclei using a linear ${ }^{13} \mathrm{C}$ chain. In this study, we chose to label our sample on both leucine/valine pro- $S$ and isoleucine- $\delta_{1}$ methyl moieties, by adding Ile- $\delta_{1}$ precursor (sodium (S)-2-hydroxy-2-(1',1'$\left.\left[{ }^{2} \mathrm{H}_{2}\right], 1^{\prime}, 2^{\prime}-\left[{ }^{13} \mathrm{C}_{2}\right]\right)$ ethyl-3-oxo-1,2,3-[ $\left[{ }^{13} \mathrm{C}_{3}\right]-4,4,4-\left[{ }^{2} \mathrm{H}_{3}\right]$-butanoate - (Kerfah et al. 2015a,b)) together with our new optimized acetolactate. The isoleucine precursor was added in the culture medium 40 min later than the new precursor in order to take into account co-incorporation incompatibilities between both the leucine/valine precursor and the isoleucine one. Indeed, enzymes from ILV-pathway have a tendency to process preferentially isoleucine precursor instead of leucine/valine precursors (Kerfah et al. 2015b, c). Incorporation of both precursors during the protein expression did not lead to a significantly different HSP90-NTD yield with regards to the yields obtained in standard $\mathrm{M} 9 /{ }^{2} \mathrm{H}_{2} \mathrm{O}$ media. No scrambling was detected neither to the pro- $R$ methyls groups of leucine and valine nor to the isoleucine- $\gamma_{2}$ site (Fig. S1a). 


\section{Connection of $I^{\delta 1} L^{\delta 2} V^{\gamma 2}$ methyl groups to $C_{\alpha}$ and $C_{\beta}$ atoms.}

Using this new precursor, it is possible to directly correlate pro- $S$ methyl groups of leucine and valine residues to their respective $\mathrm{C}_{\alpha}$ and $\mathrm{C}_{\beta}$. We decided to apply this strategy to the N-terminal domain of human HSP90 (HSP90-NTD), an extensively studied protein, whose isoform assignment ( $\alpha$ and $\beta$ ), including partial assignment of its methyl groups, is available (Jacobs et al. 2006; Elif Karagöz et al. 2011; Park et al. 2011; Lescanne et al. 2017, 2018). Here, we have focused on the N-terminal domain of the $\alpha$ isoform, a $29 \mathrm{kDa}$ protein that contains 20 isoleucine, 18 leucine and 11 valine residues. This dynamic protein is particularly challenging to assign using automatic methyl assignment methods and reported success rates are ranging from $27 \%$ to $69 \%$ (Pritišanac et al. 2017; Monneau et al. 2017; Pritišanac et al. $2019,2020)$. In our hands, only $34 \%$ of the methyl groups (30/87) could be assigned automatically with 1) a single assignment, 2) a high NOE assignment completeness of the strip related to each peak ( $>50 \%$ ) and 3 ) a high total confidence score value ( $\geq 7$ ) (Table S1) using the HSP90-NTD X-ray structure (PDB: 1YES) and experimentally detected NOE network. Therefore, this protein is a good candidate to assess our experimental strategy based on new precursors.

To do so, $200 \mu \mathrm{L}$ at $0.5 \mathrm{mM}$ of an optimally labelled sample was used to acquire three 'out and back' HCC, $\mathrm{HC}(\mathrm{C}) \mathrm{C}$ and $\mathrm{HC}(\mathrm{CC}) \mathrm{C}$ experiments (Tugarinov and Kay 2003; Ayala et al. 2009, 2012; Mas et al. 2013) connecting labelled $\mathrm{I}^{\delta 1} \mathrm{~L}^{\delta 2} \mathrm{~V}^{\gamma 2}$ methyls groups to $\mathrm{I}^{\gamma 1} \mathrm{~L}^{\gamma} \mathrm{V}^{\beta}, \mathrm{I}^{\beta} \mathrm{L}^{\beta} \mathrm{V}^{\alpha}$ and $\mathrm{I}^{\alpha} \mathrm{L}^{\alpha}$ resonances. $100 \%$ and $94 \%$ of the expected $\mathrm{C}_{\beta}$ and $\mathrm{C}_{\alpha}$ coherences, respectively, were observed for the $29 \mathrm{kDa}$ HSP90-NTD at $298 \mathrm{~K}$ ( $\tau_{\mathrm{C}}$ c.a. $20 \mathrm{~ns}$ ) (Fig. 2). The three missing $\mathrm{C}_{\alpha}$ resonances correspond to residues L56, I26 and I110, two of them being affected by extensive line broadening due to conformational exchange. With such a high percentage of observed $\mathrm{C}_{\alpha}$ and $\mathrm{C}_{\beta}$ resonances we demonstrate the applicability of this method for medium size proteins. In order to validate the strategy for larger proteins, the labelling scheme was applied to the 87 $\mathrm{kDa}$ hetero hexameric protein prefoldin from Pyrococcus horikoshii, containing $2 \alpha$ and $4 \beta$ subunits. Only the $\beta$-subunits were labelled with the optimal labelling schemes described above, whilst the $\alpha$-subunits remained perdeuterated (Fig. S1b). Three HCC experiments were collected on this $0.2 \mathrm{mM}$ sample of prefoldin at $310 \mathrm{~K}\left(\tau_{\mathrm{C}}\right.$ c.a. $\left.60 \mathrm{~ns}\right) .95 \%$ and $60 \%$ of the expected $\mathrm{C}_{\beta}$ and $\mathrm{C}_{\alpha}$ coherences, respectively, were observed (Fig. S2) despite the high molecular weight of the protein and the presence of doubled peaks due to the presence of two inequivalent $\beta$-subunits in the $\alpha_{2} \beta 4$ hexameric prefoldin (Ohtaki et al. 2008). Such HCC experiments were also acquired at $343 \mathrm{~K}\left(\tau_{\mathrm{C}}\right.$ c.a. $\left.30 \mathrm{~ns}\right)$ on this hyperthermophilic prefoldin 
1 sample, enabling transfer of assignment between backbone atoms and methyl groups (Törner 2 et al. 2021).

Application to the sequence specific assignment of $I^{\delta 1} L^{\delta 2} V^{\gamma 2}$ methyl groups of HSP90-NTD

Backbone sequential assignment was performed using 6 'BEST-TROSY' triple resonance experiments (Favier and Brutscher 2019). $\mathrm{C}_{\alpha}$ and $\mathrm{C}_{\beta}$ resonances were assigned for $89 \%$ and $80 \%$ of the residues of HSP90-NTD respectively, excluding the loosely structured N-terminal [1-16] and C-terminal [225-236] regions. The segment L103-T115, that covers the ligand binding site, is invisible by NMR due to dynamics in the $\mu$ s-ms timescale. Transfer of sequentially assigned backbones resonances to isoleucine- $\delta_{1}$, leucine- $\delta_{2}$ and valine- $\gamma_{2}$ methyl groups was achieved using 'out and back' $\mathrm{HCC}$ experiments acquired on a $\mathrm{U}-\left[{ }^{2} \mathrm{H},{ }^{15} \mathrm{~N},{ }^{13} \mathrm{C}\right]$, Ile-[2, 3, 4, 4- $\left.\left.{ }^{2} \mathrm{H}_{4} ; 1,2,3,4-{ }^{13} \mathrm{C}_{4} ;{ }^{13} \mathrm{C}^{1} \mathrm{H}_{3}\right]{ }^{\delta 1} /\left[{ }^{12} \mathrm{C}^{2} \mathrm{H}_{3}\right]^{\gamma 2}\right]$, Leu-[2, 3, 3, 4- ${ }^{2} \mathrm{H}_{4} ; 1,2,3,4-{ }^{13} \mathrm{C}_{4}$; $\left.\left.\left[{ }^{13} \mathrm{C}^{1} \mathrm{H}_{3}\right]{ }^{\text {pro- } S} /\left[{ }^{12} \mathrm{C}^{2} \mathrm{H}_{3}\right]\right]^{\text {pro- } R}\right]$, Val- $\left[2,3-{ }^{2} \mathrm{H}_{2} ; 1,2,3-{ }^{13} \mathrm{C}_{3} ;\left[{ }^{13} \mathrm{C}^{1} \mathrm{H}_{3}\right]{ }^{\text {pro- } S} /\left[{ }^{12} \mathrm{C}^{2} \mathrm{H}_{3}\right]{ }^{\text {pro- } R}\right]$ labelled HSP90-NTD sample. 2D extracts from the HCC experiments were compared with the corresponding ones from the $3 \mathrm{D} \mathrm{HNCA}$ and $\mathrm{HN}(\mathrm{CA}) \mathrm{CB}$ experiments and using $\mathrm{C}_{\alpha}$ and $\mathrm{C}_{\beta}$ resonances, all the $\mathrm{I}^{\delta 1} \mathrm{~L}^{\delta 2} \mathrm{~V}^{\gamma 2}$ methyl groups could be unambiguously connected to previously assigned backbone atoms (Fig. 2). The assignment was transferred in one step, very simply and efficiently without having to correct for the isotopic shifts (Kerfah et al. 2015a). One must note that the methyl- $\delta_{1}$ of Ile-33 and Ile-128 are superimposed in the 2D methyl-TROSY spectrum, but were unambiguously connected to the $\mathrm{C}_{\alpha}$ resonances of both amino acids (Fig. S3). Remained unassigned only methyl groups of L103, I104, L107 and I110 for which backbone atoms are NMR-invisible due to extensive conformational exchange. Therefore, single point mutagenesis was used to assign three of these last four $\mathrm{I}^{\delta 1}$ or $\mathrm{L}^{\delta 2}$ resonances (I104, L107 and I110) (Fig. 3). The remaining residue, L103, was assigned by a careful re-analysis of both HCC and backbone triple resonance experiments performed after the assignment of I104.

\section{Sequence specific assignment of $A^{\beta} M^{\varepsilon} T^{\gamma}$ methyl groups of HSP90-NTD}

In the previous $\mathrm{U}-\left[{ }^{2} \mathrm{H},{ }^{15} \mathrm{~N},{ }^{13} \mathrm{C}\right]$, Ile- $\left.\left[2,3,4,4-{ }^{2} \mathrm{H}_{4} ; 1,2,3,4-{ }^{13} \mathrm{C}_{4} ;{ }^{13} \mathrm{C}^{1} \mathrm{H}_{3}\right]{ }^{\delta 1} /\left[{ }^{12} \mathrm{C}^{2} \mathrm{H}_{3}\right]{ }^{\gamma 2}\right]$, Leu- $\left[2,3,3,4-{ }^{2} \mathrm{H}_{4} ; 1,2,3,4-{ }^{13} \mathrm{C}_{4} ;\left[{ }^{13} \mathrm{C}^{1} \mathrm{H}_{3}\right]{ }^{\text {pro }-S} /\left[{ }^{12} \mathrm{C}^{2} \mathrm{H}_{3}\right]{ }^{\text {pro- } R}\right]$, Val- $\left[2,3-{ }^{2} \mathrm{H}_{2} ; 1,2,3-{ }^{13} \mathrm{C}_{3}\right.$; $\left.\left[{ }^{13} \mathrm{C}^{1} \mathrm{H}_{3}\right]^{\text {pro- } S} /\left[{ }^{12} \mathrm{C}^{2} \mathrm{H}_{3}\right]^{\text {pro- } R}\right]$ HSP90-NTD sample, only $\mathrm{I}^{\delta 1} \mathrm{~L}^{\delta 2} \mathrm{~V}^{\gamma 2}$ methyl groups were connected to backbone by a linear ${ }^{13} \mathrm{C}$-chain. We did not incorporate labelled alanine in HSP90-NTD culture for the sample used to acquire the HCC experiments although it is commercially available with an optimal labelling pattern $\left(1,2,3-{ }^{13} \mathrm{C}_{3}, 2-{ }^{2} \mathrm{H}-\mathrm{Ala}\right)$. We recommend for future 
1 required to complete the assignment. Regarding methionine and threonine residues, their assignment cannot be undertaken using HCC experiments. Indeed, the sulfur atom present on methionine residues prevents the use of $\mathrm{HCC}$ experimens to assign methionine methyl moieties from available backbone assignment and the Thr- $\left[1,2,3-{ }^{13} \mathrm{C}, 2,3-{ }^{2} \mathrm{H}_{2},{ }^{13} \mathrm{C}^{1} \mathrm{H}_{3}-\gamma\right]$ labelled amino acid is not commercially available impeding the use of HCC 3D experiments to transfer assignment from backbone to threonine methyl groups in large proteins. Therefore, in order to assign the remaining $38 \mathrm{~A}^{\beta} \mathrm{M}^{\varepsilon}$ and $\mathrm{T}^{\gamma}$ methyl groups, we decided to use a combination of both single point mutations and through space intermethyl NOE correlation peaks. To assign the remaining $\mathrm{A}^{\beta}, \mathrm{M}^{\varepsilon}$ and $\mathrm{T}^{\gamma}$ methyl groups using inter-methyl NOE-connectivities a $\mathrm{U}-\left[{ }^{2} \mathrm{H},{ }^{15} \mathrm{~N}\right.$, $\left.{ }^{12} \mathrm{C}\right]$, Ala- $\left.\left[{ }^{13} \mathrm{C}^{1} \mathrm{H}_{3}\right]\right]^{\beta}$, Met- $\left[{ }^{13} \mathrm{C}^{1} \mathrm{H}_{3}\right]$, Leu/Val- $\left[{ }^{13} \mathrm{C}^{1} \mathrm{H}_{3}\right]{ }^{\text {pro- } S}$, Ile- $\left[{ }^{13} \mathrm{C}^{1} \mathrm{H}_{3}\right]{ }^{\delta 1}$, Thr- $\left[{ }^{13} \mathrm{C}^{1} \mathrm{H}_{3}\right]{ }^{\gamma} \mathrm{HSP} 90-$ NTD sample was required. Indeed, intermethyl NOE connectivities between previously assigned isoleucine, leucine and valine residues and unassigned $\mathrm{A}^{\beta}, \mathrm{M}^{\varepsilon}$ and $\mathrm{T}^{\gamma}$ methyl groups simplify the assignment of methionine, threonine and alanine methyl moieties.

First small-scale samples with only one type of methyl group labelled $\mathrm{A}^{\beta}, \mathrm{M}^{\varepsilon}$ or $\mathrm{T}^{\gamma}$ were prepared to identify the amino acids type corresponding to each correlation remaining to assign in the 2D methyl-TROSY spectrum. Then, we overexpressed and purified in small scale 30 single point ${ }^{13} \mathrm{C}^{1} \mathrm{H}_{3}$-labelled mutants. In order to minimize secondary chemical shifts replacement amino acids that were structurally similar to the substituted amino acid were chosen (Crublet et al. 2014) (Fig. S4).

Each of these samples containing 100 to $500 \mu \mathrm{g}$ of ${ }^{13} \mathrm{C}^{1} \mathrm{H}_{3}$-labelled single point mutant of HSP90-NTD were used to acquire a 2D SOFAST-methyl-TROSY spectrum (Amero et al 2009; Amero et al 2011) on a NMR spectrometer operating at a ${ }^{1} \mathrm{H}$ frequency of $850 \mathrm{MHz}$ and equipped with a sample changer and a $1.7 \mathrm{~mm}$ cryogenic probe head. This mutant library allowed us to assign unambiguously 27 methyl groups. Three spectra of single point mutants were more complex to analyze due to chemical shift perturbations that result from the introduced mutation (Fig. S5). Out of the $38 \mathrm{~A}^{\beta}, \mathrm{M}^{\varepsilon}$ and $\mathrm{T}^{\gamma}$ methyl groups, eleven remained unassigned after the first analysis of the mutant library, among them eight methyls (one $\mathrm{M}^{\varepsilon}$, two $\mathrm{A}^{\beta}$ and five $\mathrm{T}^{\gamma}$ methyl groups) for which mutants were not available and three $\mathrm{T}^{\gamma}$ methyl groups whose mutant spectra were challenging to analyze. The sole unassigned methionine methyl signal was unambiguously assigned as the last remaining methionine residue (M98).

To complete the assignment for the last 10 methyl groups, a $0.5 \mathrm{mM}$ sample of $\mathrm{U}-\left[{ }^{2} \mathrm{H}\right.$, $\left.{ }^{15} \mathrm{~N},{ }^{12} \mathrm{C}\right]$, Ala- $\left[{ }^{13} \mathrm{C}^{1} \mathrm{H}_{3}\right]{ }^{\beta}$, Met- $\left[{ }^{13} \mathrm{C}^{1} \mathrm{H}_{3}\right]$, Leu/Val- $\left[{ }^{13} \mathrm{C}^{1} \mathrm{H}_{3}\right]{ }^{\text {proS }}$, Ile- $\left[{ }^{13} \mathrm{C}^{1} \mathrm{H}_{3}\right]{ }^{\delta 1}$, Thr- $\left[{ }^{13} \mathrm{C}^{1} \mathrm{H}_{3}\right]{ }^{\gamma}$ labelled HSP90-NTD was prepared to acquire a 3D HMQC-NOESY-HMQC. A total of 344 intermethyl NOEs cross peaks with a $\mathrm{S} / \mathrm{N} \geq 5$ were detected between methyls distant by up to 
110 A. Examples of intermethyl NOE and a matrix presenting all the observed NOEs are 2 displayed in Fig. 4. To assign the remaining 2 alanines and 8 threonines, the NOE connectivities 3 and the previously assigned methyls (49 $\mathrm{I}^{\delta 1} \mathrm{~L}^{\delta 2} \mathrm{~V}^{\gamma 2}$ and $28 \mathrm{~A}^{\beta} \mathrm{M}^{\varepsilon}$ and $\mathrm{T}^{\gamma}$ methyl groups) were 4 used as input for the program MAGIC. Six methyl groups (2 alanines (A141 and A145) and 4 5 threonines (T90, T88, T115 and T149)) were unambiguously assigned with both a high 6 percentage of NOE correlation peaks assigned and a high confidence score. Four threonines 7 (T94, T109, T176 and T184) were left either with multiple assignments or an assignment with 8 a low confidence score. However, taking into account the information obtained from the NOE9 based assignment, the mutant spectra displaying chemical shift perturbations (Fig. S5) were carefully reanalyzed allowing us to assign the four remaining threonine methyl signals.

Finally, all the 87 methyl groups of HSP90-NTD were assigned using both isoleucine precursor and the newly labelled acetolactate for isoleucine, leucine and valine methyl groups and this mixed NOE/mutants strategy for alanine, methionine and threonine methyl moieties (Fig. 5, Table S2). It can be noted that, there is, indeed, an overlap of two isoleucines (I33/I128) explaining only 86 visible peaks. Even though dynamics in the intermediate regime broaden the backbone resonances of the segment which is covering the ATP binding site [103-115] beyond the detection threshold, the according methyl probes are visible. The assignment of L103, I104, L107, T109, I110, A111 and T115 render this previously invisible region amenable to NMR studies. 


\section{Conclusion:}

This research reports the synthesis of a new dissymmetric ${ }^{13} \mathrm{C} /{ }^{2} \mathrm{H}$-labelled acetolactate, a precursor that allows to connect directly, via linear ${ }^{13} \mathrm{C}$ chains, backbone atoms to the pro- $S$ methyl groups of leucine and valine residues. This optimized precursor can be combined with isoleucine precursor and ${ }^{2} \mathrm{H} /{ }^{13} \mathrm{C}$-alanine to enable the transfer of assignment from backbone to methyl groups with only one sample without requiring the correction of ${ }^{1} \mathrm{H} /{ }^{2} \mathrm{H}$ isotopic chemical shift for the ${ }^{13} \mathrm{C}$ resonances. We expect that this new precursor will ease the assignment of leucine and valine pro- $S$ methyl groups of proteins using already assigned backbone resonances as it simplifies the analysis of the NMR experiments. This innovative labelling scheme was applied to the $29 \mathrm{kDa} \mathrm{N}$-terminal domain of human HSP90 protein and to the $87 \mathrm{kDa}$ hetero hexameric prefoldin complex. Using both isoleucine precursor and the newly labelled acetolactate, we managed to simply and efficiently transfer the backbone sequential assignment to all the isoleucine- $\delta_{1}$, leucine and valine pro- $S$ methyl moieties of HSP90-NTD. This allowed us to confirm or correct the residue specific assignment of most isoleucine, leucine and valine methyl groups (2 assignments were corrected for the 49 ILV residues - Table S2) and the stereospecific assignment of prochiral methyl groups (5 stereospecific assignments were inverted for the 29 leucine and valine residues - Table S2). In addition to the full assignment of $I^{\delta 1} L^{\delta 2} \mathrm{~V}^{\gamma 2}$ methyl groups, we have used a mixed strategy based on mutagenesis and intermethyl NOEs to assign 38 new methyl resonances corresponding to the $A^{\beta} M^{\varepsilon} T^{\gamma}$ methyl moieties of HSP90-NTD. Hence, we show that, despite extended conformational exchange that impedes the complete backbone assignment, we managed to detect and assign signals for all methyl probes including the ones belonging to the segment covering HSP90 ATP binding site. 


\section{Data availability}

3 The FIDs acquired for this study are available in the biological magnetic resonance databank

4 (bmrbig12) and the assignment have been deposited under the BMRB ID: 50786.

5

6

\section{Acknowledgments}

8 The authors thank Dr. R Awad and Mr. L. Imbert for advice and stimulating discussions. This

9 work used the high field NMR and isotopic labelling facilities at the Grenoble Instruct-ERIC 10 Center (ISBG; UMS 3518 CNRS-CEA-UGA-EMBL) within the Grenoble Partnership for 11 Structural Biology (PSB). Platform access was supported by FRISBI (ANR-10-INBS-05-02) 12 and GRAL, a project of the University Grenoble Alpes graduate school (Ecoles Universitaires 13 de Recherche) CBH-EUR-GS (ANR-17-EURE-0003). IBS acknowledges integration into the 14 Interdisciplinary Research Institute of Grenoble (IRIG, CEA). This work was supported by 15 grants from CEA/NMR-Bio (research program C24990) and by the French National Research 16 Agency in the framework of the "Investissements d'avenir" program (ANR-15-IDEX-02). 


\section{References}

Amero C, Asunción Durá M, Noirclerc-Savoye M, et al (2011) A systematic mutagenesisdriven strategy for site-resolved NMR studies of supramolecular assemblies. J Biomol NMR 50:229-236. https://doi.org/10.1007/s10858-011-9513-5

Amero C, Schanda P, Asunción Durá M, et al (2009) Fast Two-Dimensional NMR Spectroscopy of High Molecular Weight Protein Assemblies. J Am Chem Soc 131:34483449. https://doi.org/10.1021/ja809880p

Ayala I, Chiari L, Kerfah R, et al (2020) Asymmetric Synthesis of Methyl Specifically Labelled L-Threonine and Application to the NMR Studies of High Molecular Weight Proteins. ChemistrySelect 5:5092-5098. https://doi.org/10.1002/slct.202000827

Ayala I, Hamelin O, Amero C, et al (2012) An optimized isotopic labelling strategy of isoleucine- $\gamma 2$ methyl groups for solution NMR studies of high molecular weight proteins. Chem Commun 48:1434-1436. https://doi.org/10.1039/c1cc12932e

Ayala I, Sounier R, Usé N, et al (2009) An efficient protocol for the complete incorporation of methyl-protonated alanine in perdeuterated protein. J Biomol NMR 43:111-119. https://doi.org/10.1007/s10858-008-9294-7

Chao F-A, Kim J, Xia Y, et al (2014) FLAMEnGO 2.0: An enhanced fuzzy logic algorithm for structure-based assignment of methyl group resonances. J Magn Reson 245:17-23. https://doi.org/10.1016/jjmr.2014.04.012

Crublet E, Kerfah R, Mas G, et al (2014) A cost-effective protocol for the parallel production of libraries of CH3-specifically labeled mutants for NMR studies of high molecular weight proteins. Methods Mol Biol 1091:229-243. https://doi.org/10.1007/978-1-62703-6917 - 17

Delaglio F, Grzesiek S, Vuister GW, et al (1995) NMRPipe: A multidimensional spectral processing system based on UNIX pipes. J Biomol NMR 6:277-293. https://doi.org/10.1007/BF00197809

Elif Karagöz G, Duarte AMS, Ippel H, et al (2011) N-terminal domain of human Hsp90 triggers binding to the cochaperone p23. 108:580-585. https://doi.org/10.1073/pnas.1011867108//DCSupplemental

Epstein J, Cannon P, Swidler R, Baraze A (1977) Amplification of cyanide ion production by the micellar reaction of keto oximes with phosphono- and phosphorofluoridates. J Org Chem 42:759-762. https://doi.org/10.1021/jo00424a043

Favier A, Brutscher B (2019) NMRlib: user-friendly pulse sequence tools for Bruker NMR 
spectrometers. J Biomol NMR 73:199-211. https://doi.org/10.1007/s10858-019-00249-1

Gans P, Hamelin O, Sounier R, et al (2010) Stereospecific isotopic labeling of methyl groups for NMR spectroscopic studies of high-molecular-weight proteins. Angew Chemie - Int Ed 49:1958-1962. https://doi.org/10.1002/anie.200905660

Gardner KH, Kay LE, Chinchilla D, Fisher K (1997) Production and Incorporation of 15 N, 13 C, 2 H ( $1 \mathrm{H}-\delta 1$ Methyl) Isoleucine into Proteins for Multidimensional NMR Studies. J Am Chem Soc 119:7599-7600

Gauto DF, Estrozi LF, Schwieters CD, et al (2019) Integrated NMR and cryo-EM atomicresolution structure determination of a half-megadalton enzyme complex. Nat Commun 10:2697: https://doi.org/10.1038/s41467-019-10490-9

Gelis I, Bonvin AMJJ, Keramisanou D, et al (2007) Structural basis for signal sequence recognition by the 204-kDa translocase motor SecA determined by NMR. Cell 131:756769. https://doi.org/10.1016/j.cell.2007.09.039

Goto NK, Gardner KH, Mueller GA, et al (1999) A robust and cost-effective method for the production of Val, Leu, Ile $(\delta 1)$ methyl-protonated $15 \mathrm{~N}-, 13 \mathrm{C}-, 2 \mathrm{H}$-labeled proteins. J Biomol NMR 13:369-374

Gross JD, Gelev VM, Wagner G (2003) A sensitive and robust method for obtaining intermolecular NOEs between side chains in large protein complexes. J Biomol NMR 25:235-242

Hajduk PJ, Augeri DJ, Mack J, et al (2000) NMR-based screening of proteins containing 13C-labeled methyl groups. J Am Chem Soc 122:7898-7904. https://doi.org/10.1021/ja0003501

Isaacson RL, Simpson PJ, Liu M, et al (2007) A new labeling method for methyl transverse relaxation-optimized spectroscopy NMR spectra of alanine residues. J Am Chem Soc 129:15428-15429. https://doi.org/10.1021/ja0761784

Jacobs DM, Langer T, Elshorst B, et al (2006) NMR Backbone Assignment of the N-terminal Domain of Human HSP90. J. Biomol. NMR 36:52

Kerfah R, Hamelin O, Boisbouvier J, Marion D (2015a) CH3-specific NMR assignment of alanine, isoleucine, leucine and valine methyl groups in high molecular weight proteins using a single sample. J Biomol NMR 63:389-402. https://doi.org/10.1007/s10858-0159998-4

Kerfah R, Plevin MJ, Pessey O, et al (2015b) Scrambling free combinatorial labeling of alanine- $\beta$, isoleucine- $\delta 1$, leucine-proS and valine-proS methyl groups for the detection of long range NOEs. J Biomol NMR 61:73-82. https://doi.org/10.1007/s10858-014-9887-2 
1 Kerfah R, Plevin MJ, Sounier R, et al (2015c) Methyl-specific isotopic labeling: a molecular tool box for solution NMR studies of large proteins. Curr Opin Struct Biol 32:113-122. https://doi.org/10.1016/j.sbi.2015.03.009

Lapinaite A, Simon B, Skjaerven L, et al (2013) The structure of the box C/D enzyme reveals regulation of RNA methylation. Nature 502:519-523. https://doi.org/10.1038/nature12581

Lescanne M, Ahuja P, Blok A, et al (2018) Methyl group reorientation under ligand binding probed by pseudocontact shifts. J Biomol NMR 71:275-285. https://doi.org/10.1007/s10858-018-0190-5

Lescanne M, Skinner SP, Blok A, et al (2017) Methyl group assignment using pseudocontact shifts with PARAssign. J Biomol NMR 69:183-195. https://doi.org/10.1007/s10858017-0136-3

Mas G, Crublet E, Hamelin O, et al (2013) Specific labeling and assignment strategies of valine methyl groups for NMR studies of high molecular weight proteins. J Biomol NMR 57:251-262. https://doi.org/10.1007/s10858-013-9785-z

Mas G, Guan J-Y, Crublet E, et al (2018) Structural investigation of a chaperonin in action reveals how nucleotide binding regulates the functional cycle. Sci Adv 4:eaau:4196. https://doi.org/doi: 10.1126/sciadv.aau4196

Monneau YR, Rossi P, Bhaumik A, et al (2017) Automatic methyl assignment in large proteins by the MAGIC algorithm. J Biomol NMR 69:215-227. https://doi.org/10.1007/s10858017-0149-y

Nerli S, De Paula VS, McShan AC, Sgourakis NG (2021) Backbone-independent NMR resonance assignments of methyl probes in large proteins. Nat Commun 12:691. https://doi.org/10.1038/s41467-021-20984-0

Ohtaki A, Kida H, Miyata Y, et al (2008) Structure and Molecular Dynamics Simulation of Archaeal Prefoldin: The Molecular Mechanism for Binding and Recognition of Nonnative Substrate Proteins. J Mol Biol 376:1130-1141. https://doi.org/10.1016/j.jmb.2007.12.010

Park SJ, Kostic M, Dyson HJ (2011) Dynamic interaction of Hsp90 with its client protein p53 411(1):158-173. J Mol Biol. https://doi.org/10.1016/j.jmb.2011.05.030

Pritišanac I, Alderson TR, Güntert P (2020) Automated assignment of methyl NMR spectra from large proteins. Prog Nucl Magn Reson Spectrosc 118-119:54-73. https://doi.org/10.1016/j.pnmrs.2020.04.001

Pritišanac I, Degiacomi MT, Alderson TR, et al (2017) Automatic Assignment of MethylNMR Spectra of Supramolecular Machines Using Graph Theory. J Am Chem Soc 
139:9523-9533. https://doi.org/10.1021/jacs.6b11358

Pritišanac I, Würz JM, Alderson TR, Güntert P (2019) Automatic structure-based NMR methyl resonance assignment in large proteins. Nat Commun 10:4922: https://doi.org/10.1038/s41467-019-12837-8

Rosenzweig R, Moradi S, Zarrine-Afsar A, et al (2013) Unraveling the Mechanismof Protein Disaggregation Througha ClpB-DnaK Interaction. Science (80- ) 339:1080-1083. https://doi.org/10.1126/science.1233066

Sounier R, Blanchard L, Wu Z, Boisbouvier J (2007) High-accuracy distance measurement between remote methyls in specifically protonated proteins. J Am Chem Soc 129:472473. https://doi.org/10.1021/ja067260m

Sprangers R, Kay LE (2007) Quantitative dynamics and binding studies of the 20S proteasome by NMR. Nature 445:618-622. https://doi.org/10.1038/nature05512

Stoffregen MC, Schwer MM, Renschler FA, Wiesner S (2012) Methionine scanning as an NMR tool for detecting and analyzing biomolecular interaction surfaces. Structure 20:573-581. https://doi.org/10.1016/j.str.2012.02.012

Törner R, Awad R, Gans P, et al (2020) Spectral editing of intra- and inter-chain methyl-methyl NOEs in protein complexes. J Biomol NMR 74:83-94. https://doi.org/10.1007/s10858019-00293-x

Törner R, Henot F, Awad R, et al (2021) Backbone and methyl resonances assignment of the $87 \mathrm{kDa}$ prefoldin from Pyrococcus horikoshii. Biomol NMR Assignment. https://doi.org/10.1007/s12104-021-10029-4

Tugarinov V, Hwang PM, Ollerenshaw JE, Kay LE (2003) Cross-correlated relaxation enhanced 1H-13C NMR spectroscopy of methyl groups in very high molecular weight proteins and protein complexes. J Am Chem Soc 125:10420-10428. https://doi.org/10.1021/ja030153x

Tugarinov V, Kay LE (2003) Ile, Leu, and Val Methyl Assignments of the 723-Residue Malate Synthase G Using a New Labeling Strategy and Novel NMR Methods. J Am Chem Soc 125:13868-13878. https://doi.org/10.1021/ja030345s

Tugarinov V, Kay LE (2004a) Stereospecific NMR assignments of prochiral methyls, rotameric states and dynamics of valine residues in malate synthase G. J Am Chem Soc 126:98279836. https://doi.org/10.1021/ja048738u

Tugarinov V, Kay LE (2004b) An isotope labeling strategy for methyl TROSY spectroscopy. J Biomol NMR 28:165-172

Tugarinov V, Kay LE, Ibraghimov I, Orekhov VY (2005) High-resolution four-dimensional 
1H-13C NOE spectroscopy using methyl-TROSY, sparse data acquisition, and multidimensional decomposition. J Am Chem Soc 127:2767-2775.

3 https://doi.org/10.1021/ja044032o

4 Velyvis A, Ruschak AM, Kay LE (2012) An Economical Method for Production of 2H,13CH35 Threonine for Solution NMR Studies of Large Protein Complexes: Application to the 670 kDa Proteasome. PLoS One 7:e43725 https://doi.org/10.1371/journal.pone.0043725

Vranken WF, Boucher W, Stevens TJ, et al (2005) The CCPN data model for NMR spectroscopy: Development of a software pipeline. Proteins Struct Funct Genet 59:687696. https://doi.org/10.1002/prot.20449

Xu Y, Matthews S (2013) MAP-XSII: An improved program for the automatic assignment of 1 methyl resonances in large proteins. J Biomol NMR 55:179-187. https://doi.org/10.1007/s10858-012-9700-z 
<smiles></smiles><smiles>CCOC(=O)[13C](=O)[13C](C)=O</smiles><smiles>CCOC(=O)[13C](=O)[13C](C)=O</smiles><smiles>[GeH3]</smiles><smiles>C[13C](=O)[13C]([13CH3])([18OH])[13C](=O)[O-]</smiles>

Fig. 1 Synthetic scheme for preparation of specifically labelled sodium 1, 2, 3- $\left[{ }^{13} \mathrm{C}_{3}\right]-2-$ $\left[{ }^{13} \mathrm{C}^{1} \mathrm{H}_{3}\right]-2-\left[\mathrm{O}^{2} \mathrm{H}\right]-3$-oxo-4, 4, 4- $\left[{ }^{2} \mathrm{H}_{3}\right]$-butanoate. a) i-LiHMDS (2.1 equiv.), dry THF, $-78^{\circ} \mathrm{C}$; ii-1,2- $\left[{ }^{13} \mathrm{C}_{2}\right]$-ethyl acetate (1 equiv.), $-78^{\circ} \mathrm{C}, 15 \mathrm{~min}$.; iii-1- $\left[{ }^{13} \mathrm{C}\right]$-acetyl chloride (1.0 equiv.), $78^{\circ} \mathrm{C}, 30$ min.; iv- ${ }^{1} \mathrm{HCl} 20 \%$; b) $\mathrm{K}_{2} \mathrm{CO}_{3}$ (1.1 equiv.), ${ }^{13} \mathrm{C}^{1} \mathrm{H}_{3} \mathrm{I}$ (1.1 equiv.), $0{ }^{\circ} \mathrm{C}, 18 \mathrm{~h}, \mathrm{EtO}^{1} \mathrm{H}$; c) $\mathrm{Cs}_{2} \mathrm{CO}_{3}$ (0.2 equiv.), $\mathrm{P}(\mathrm{OEt})_{3}\left(0.2\right.$ equiv.), $\mathrm{O}_{2}$, DMSO, 20h. d) $\mathrm{i}-\mathrm{NaO}^{2} \mathrm{H}(2.5 \mathrm{M}),{ }^{2} \mathrm{H}_{2} \mathrm{O}$; ii${ }^{2} \mathrm{HCl} 35 \%$; Tris buffer pH 7.5; $27 \%$ overall yield. 

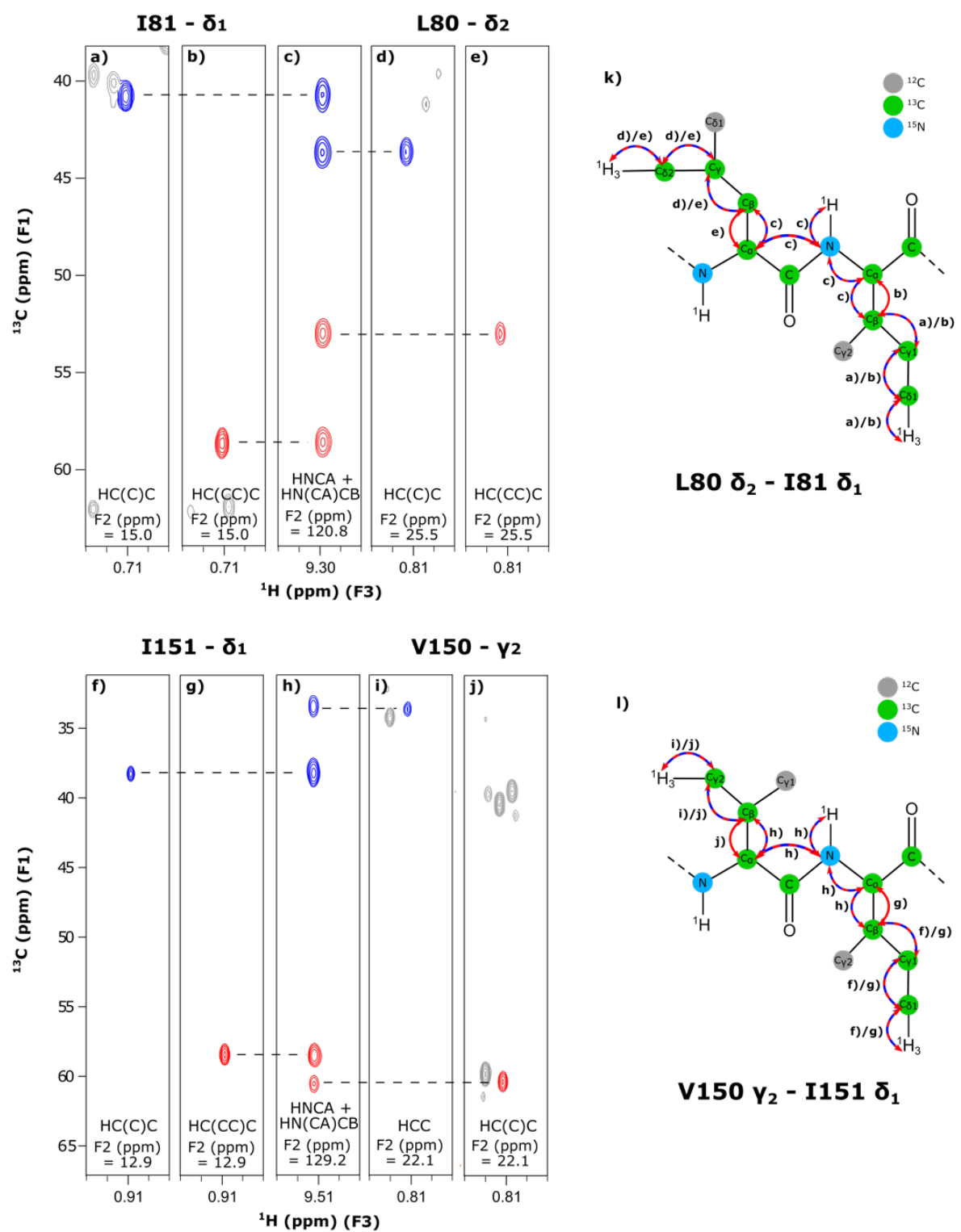

Fig. 2 Assignment transfer from the backbone to $L e u^{\text {pro- } S}$, Val ${ }^{\text {pro- } S}$ and Ile- $\delta_{1}$ methyl groups of 3 HSP90-NTD. Examples of 2D-extracts from 3D 'out and back' HCC (i), HC(C)C (a, d, f and j) 4 and $\mathrm{HC}(\mathrm{CC}) \mathrm{C}(\mathrm{b}$, e and $\mathrm{g})$ experiments correlating ${ }^{1} \mathrm{H}\left(\mathrm{F}_{3}\right)$ and ${ }^{13} \mathrm{C}\left(\mathrm{F}_{2}\right)$ methyl resonances with ${ }^{13} \mathrm{C}_{\beta}$ (blue) or ${ }^{13} \mathrm{C}_{\alpha}$ (red) in $\mathrm{F}_{1}$ dimension. Panels $\mathrm{c}$ and h display the corresponding 2D HNCA and $\mathrm{HN}(\mathrm{CA}) \mathrm{CB}$ extracts for Ile-81 (c) and Ile-151 (h) allowing to connect Leu-80- $\delta_{2}$ (pro- $S$ ),

7 Ile-81- $\delta_{1}$, Val-150- $\gamma_{2}$ (pro-S), Ile-151- $\delta_{1}$ methyl groups to previously assigned backbone atoms.

8 3D spectra were recorded on an NMR spectrometer operating at a proton frequency of $600 \mathrm{MHz}$ 9 using the U- $\left[{ }^{2} \mathrm{H},{ }^{15} \mathrm{~N},{ }^{13} \mathrm{C}\right]$, Ile- $\left.\left[2,3,4,4-{ }^{2} \mathrm{H}_{4} ; 1,2,3,4-{ }^{13} \mathrm{C}_{4} ;{ }^{13} \mathrm{C}^{1} \mathrm{H}_{3}\right]{ }^{\delta 1} /\left[{ }^{12} \mathrm{C}^{2} \mathrm{H}_{3}\right]{ }^{\gamma 2}\right]$, Leu-[2, 3, $\left.10 \quad 3,4-{ }^{2} \mathrm{H}_{4} ; 1,2,3,4-{ }^{13} \mathrm{C}_{4} ;\left[{ }^{13} \mathrm{C}^{1} \mathrm{H}_{3}\right]{ }^{\text {pro }-\mathrm{S}} /\left[{ }^{12} \mathrm{C}^{2} \mathrm{H}_{3}\right]{ }^{\text {pro- } R}\right]$, Val- $\left[2,3-{ }^{2} \mathrm{H}_{2} ; 1,2,3-{ }^{13} \mathrm{C}_{3} ;\left[{ }^{13} \mathrm{C}^{1} \mathrm{H}_{3}\right]{ }^{\text {pro- }}\right.$ $\left.11 S /\left[{ }^{12} \mathrm{C}^{2} \mathrm{H}_{3}\right]{ }^{\text {pro- } R}\right]$ labelled sample or $\mathrm{U}-\left[{ }^{2} \mathrm{H},{ }^{15} \mathrm{~N},{ }^{13} \mathrm{C}\right]$ labelled sample (3D $\mathrm{HNCA}$ and $12 \mathrm{HN}(\mathrm{CA}) \mathrm{CB}) .(\mathrm{k})$ and (l) represent magnetization transfer schemes correlating with the strips 13 (a, b, c, d, e) and (f, g, h, i, j), respectively. Except when specified, all hydrogen atoms are ${ }^{2} \mathrm{H}$. 
3

4

5

6

7

8

9

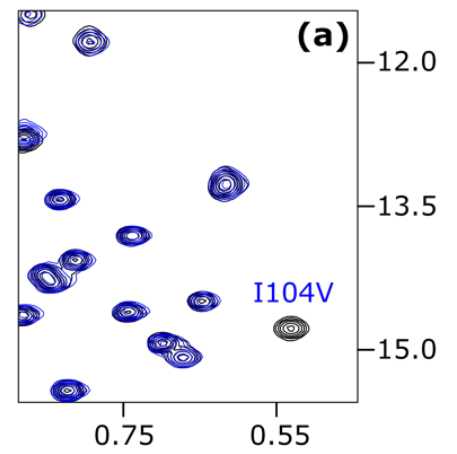

${ }^{1} \mathrm{H}$ (ppm)

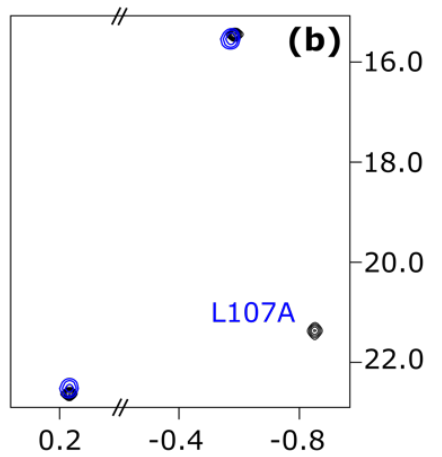

${ }^{1} \mathrm{H}$ (ppm)

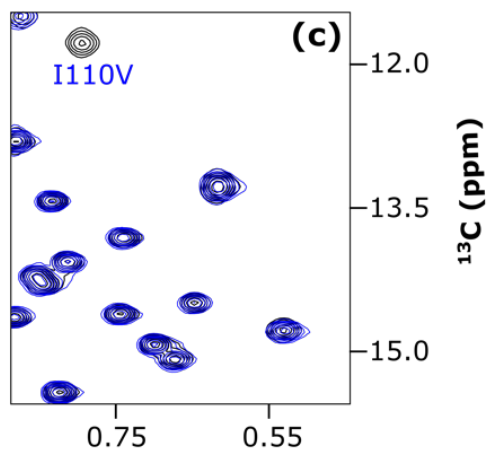

${ }^{1} \mathbf{H}$ (ppm)

Fig. 3 Assignment of HSP90-NTD methyl groups belonging to the flexible loop covering ATP binding site. The 2D SOFAST methyl TROSY spectra were recorded using either the isoleucine to valine mutant samples using $\mathrm{U}-\left[{ }^{2} \mathrm{H},{ }^{12} \mathrm{C},{ }^{15} \mathrm{~N}\right]-\mathrm{Ile}-\left[{ }^{13} \mathrm{C}^{1} \mathrm{H}_{3}\right]{ }^{\delta 1}$ labelling scheme, or the leucine to alanine mutant sample using $\mathrm{U}-\left[{ }^{2} \mathrm{H},{ }^{12} \mathrm{C},{ }^{15} \mathrm{~N}\right]-\mathrm{Leu} / \mathrm{Val}-\left[{ }^{13} \mathrm{C}^{1} \mathrm{H}_{3}\right]{ }^{\text {pro- } S}$ labelling scheme. Spectra were recorded at $298 \mathrm{~K}$ on a NMR spectrometer operating at a proton frequency of $850 \mathrm{MHz}$. a) The HSP90-NTD mutant spectra of I104V. b) L107A. c) I110V. Each mutant spectrum extract (dark blue) was superimposed with the wild type protein extract (black). 

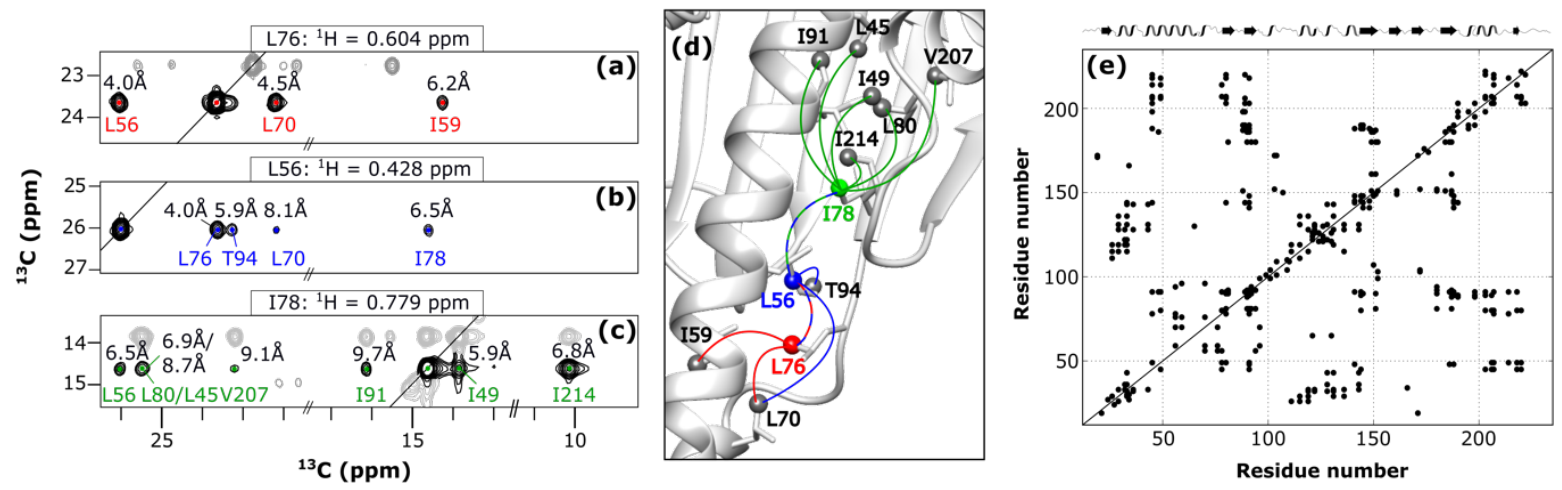

Fig. 4 Detected intermethyl NOEs in human HSP90-NTD. a-c Examples of 2D extracts of a 3D HMQC-NOESY-HMQC experiment recorded using U- $\left[{ }^{2} \mathrm{H},{ }^{12} \mathrm{C},{ }^{15} \mathrm{~N}\right]-\mathrm{Leu} / \mathrm{Val}-\left[{ }^{13} \mathrm{C}^{1} \mathrm{H}_{3}\right]^{\text {pro- } S}$, Ile- $\left[{ }^{13} \mathrm{C}^{1} \mathrm{H}_{3}\right]^{\delta 1}$, Met- $\left[{ }^{13} \mathrm{C}^{1} \mathrm{H}_{3}\right]^{\varepsilon}$, Ala- $\left[{ }^{13} \mathrm{C}^{1} \mathrm{H}_{3}\right]^{\beta}$, Thr- $\left[{ }^{13} \mathrm{C}^{1} \mathrm{H}_{3}\right]^{\gamma}$ HSP90-NTD sample on a NMR spectrometer operating at a proton frequency of $950 \mathrm{MHz}$. The planes were extracted at the methyl proton frequencies of L76 (a), L56 (b) and I78 (c). The NOEs detected are colored in red, blue and green, respectively. $\mathbf{d}$ The NOEs detected in $2 \mathrm{D}$ extracts presented in panels a-c are displayed on the 3D structure of HSP90-NTD (PDB: 1YES) by lines (red for L76, blue for L56 and green for I78). e 2D matrix representing all the HSP90-NTD methyl residue pairs for which NOE cross-peaks have been detected. 


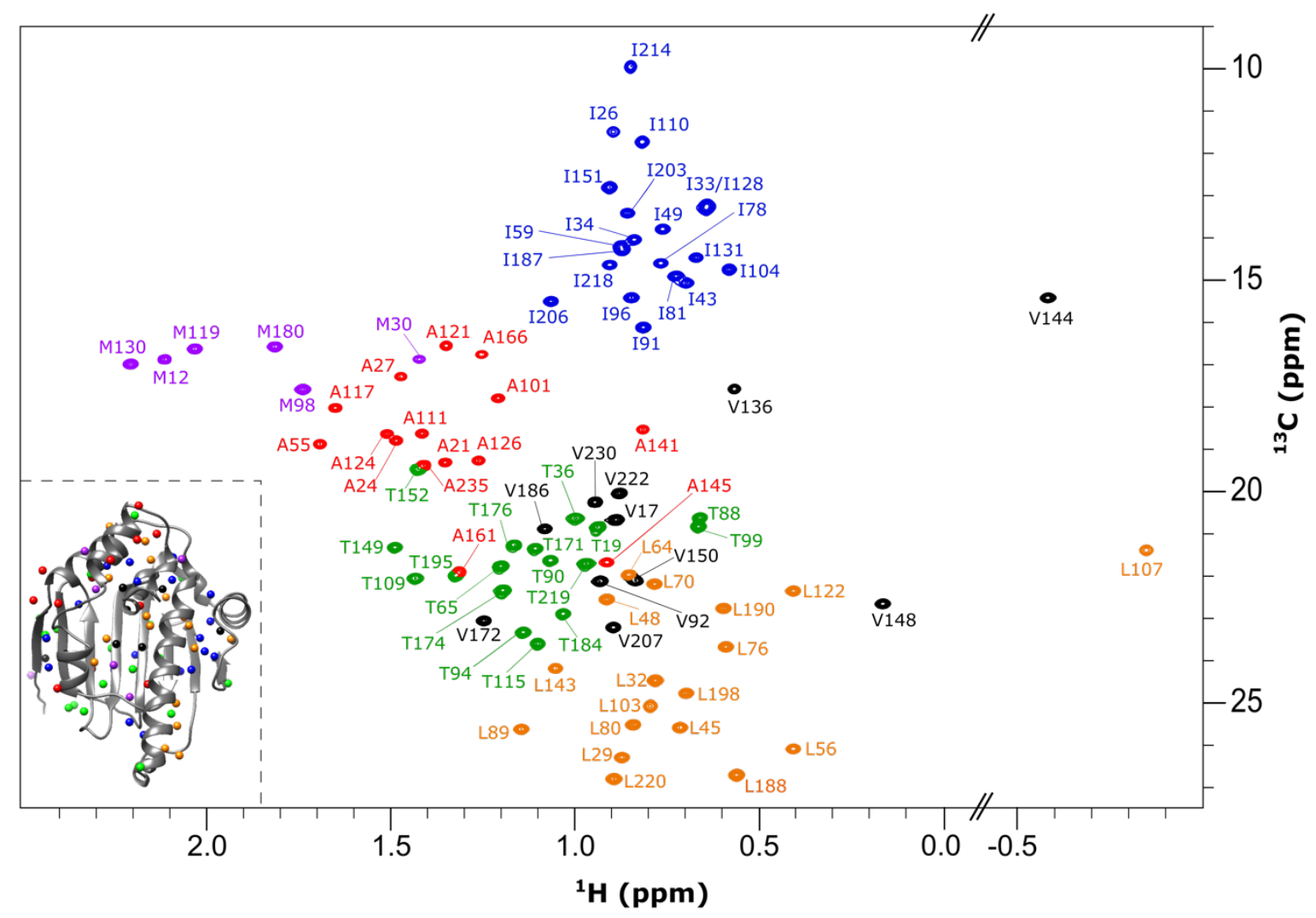

\section{.}

Fig. 5 Assigned 2D ${ }^{1} \mathrm{H}-{ }^{13} \mathrm{C}$ SOFAST methyl TROSY spectrum of apo HSP90-NTD. Human HSP90-NTD was perdeuterated and specifically ${ }^{13} \mathrm{C}^{1} \mathrm{H}_{3}$-labelled on Leu/Val- $\left.\left[{ }^{13} \mathrm{C}^{1} \mathrm{H}_{3}\right]\right]^{\text {pro- } S}$, Ile$\left[{ }^{13} \mathrm{C}^{1} \mathrm{H}_{3}\right]^{\delta 1}$, Met- $\left.\left[{ }^{13} \mathrm{C}^{1} \mathrm{H}_{3}\right]\right]^{\varepsilon}$, Ala- $\left[{ }^{13} \mathrm{C}^{1} \mathrm{H}_{3}\right]{ }^{\beta}$, Thr- $\left[{ }^{13} \mathrm{C}^{1} \mathrm{H}_{3}\right]{ }^{\gamma}$ methyl groups. Each signal is annotated with the corresponding residue number. The spectrum was recorded on a NMR spectrometer operating at a proton frequency of $950 \mathrm{MHz}$. On the bottom left side an insert represents the 3D structure of human HSP90-NTD (PDB: 1YES). The methyl groups are represented by spheres. Alanines, isoleucines, valines, leucines, threonines and methionines are depicted in red, dark blue, black, orange, light green and purple, respectively. 
Optimized Precursor to Simplify Assignment Transfer between Backbone Resonances and Stereospecifically labelled Valine and Leucine Methyl Groups: Application to Human Hsp90 N-Terminal Domain (1)

Faustine Henot ${ }^{1}$, Rime Kerfah ${ }^{2}$, Ricarda Törner ${ }^{1}$, Pavel Macek ${ }^{1,2}$, Elodie Crublet $^{2}$, Pierre Gans $^{1}$, Matthias Frech ${ }^{3}$, Olivier Hamelin ${ }^{4}$, Jerome Boisbouvier ${ }^{1, *}$

1. Univ. Grenoble Alpes, CNRS, CEA, Institut de Biologie Structurale (IBS),

71, avenue des martyrs, F-38044 Grenoble, France.

2. NMR-Bio, 5 place Robert Schuman, F-38025 Grenoble, France.

3. Discovery Technologies, Merck KGaA, Frankfurter Straße 250, 64293 Darmstadt, Germany.

4. Univ. Grenoble Alpes, CEA, CNRS, IRIG, CBM-F-38000 Grenoble. France.

* correspondence to be addressed to: jerome.boisbouvier@ibs.fr

\section{SUPPLEMENTARY INFORMATION}



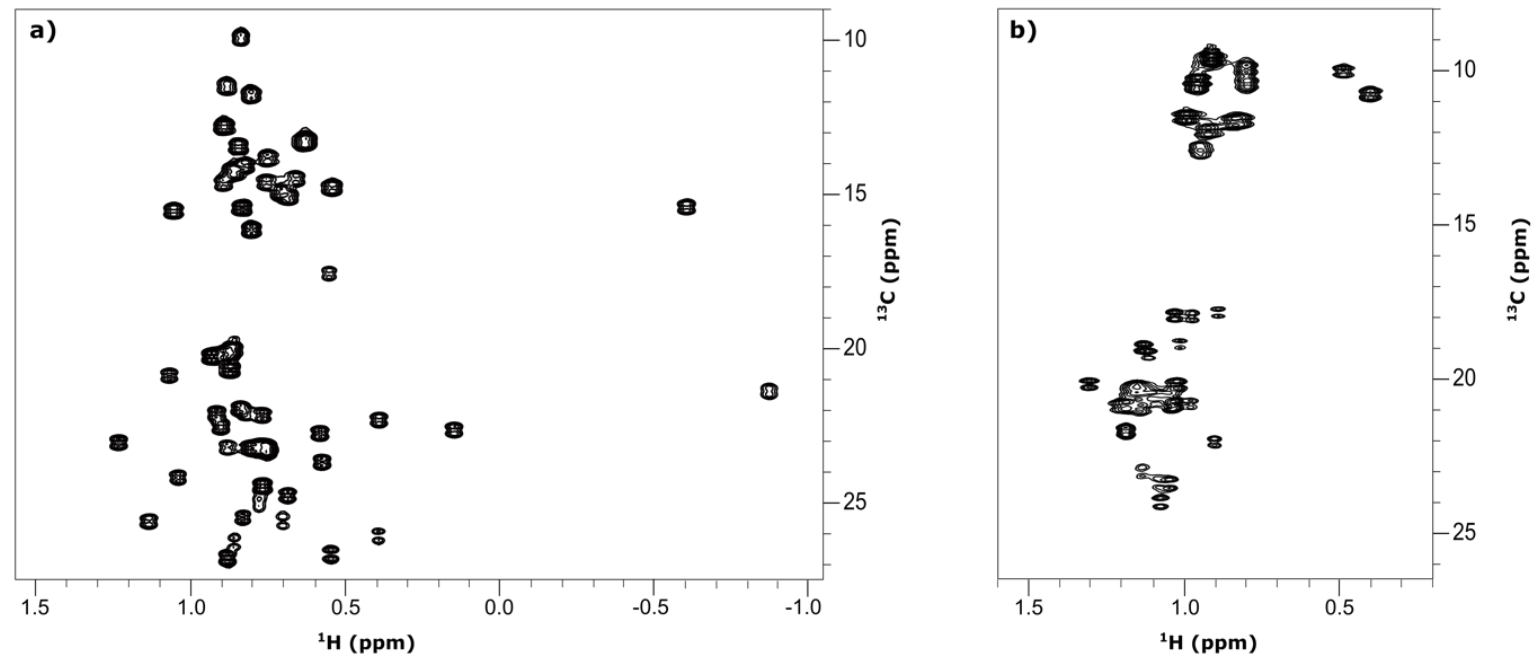

Fig. S1 2D ${ }^{1} \mathrm{H}-{ }^{13} \mathrm{C}$ SOFAST methyl TROSY spectrum of $\mathrm{U}-\left[{ }^{2} \mathrm{H},{ }^{15} \mathrm{~N},{ }^{13} \mathrm{C}\right]$, Ile- $\left[2,3,4,4-{ }^{2} \mathrm{H}_{4}\right.$; $\left.\left.1,2,3,4-{ }^{13} \mathrm{C}_{4} ;{ }^{13} \mathrm{C}^{1} \mathrm{H}_{3}\right]{ }^{\delta 1} /\left[{ }^{12} \mathrm{C}^{2} \mathrm{H}_{3}\right]{ }^{\gamma 2}\right]$, Leu- $\left[2,3,3,4-{ }^{2} \mathrm{H}_{4} ; 1,2,3,4-{ }^{13} \mathrm{C}_{4} ;\left[{ }^{13} \mathrm{C}^{1} \mathrm{H}_{3}\right]{ }^{\text {pro- }} /\left[{ }^{12} \mathrm{C}^{2} \mathrm{H}_{3}\right]\right]^{\text {pro- }}$ ${ }^{R}$, Val-[2, $\left.3-{ }^{2} \mathrm{H}_{2} ; 1,2,3-{ }^{13} \mathrm{C}_{3} ;\left[{ }^{13} \mathrm{C}^{1} \mathrm{H}_{3}\right]^{\text {pro- } S} /\left[{ }^{12} \mathrm{C}^{2} \mathrm{H}_{3}\right]^{\text {pro- } R}\right]$ HSP90-NTD a) and prefoldin b) samples (labelling scheme A applied to prefoldin $\beta$ subunit only), recorded before the HCC experiments to check the sample quality. The labelling strategy used Ile- $\delta_{1}$ precursor: sodium (S)-2-hydroxy-2-(1',1'-[ $\left.\left[{ }^{2} \mathrm{H}_{2}\right], 1^{\prime}, 2^{\prime}-\left[{ }^{13} \mathrm{C}_{2}\right]\right)$ ethyl-3-oxo-1,2,3-[ $\left.{ }^{13} \mathrm{C}_{3}\right]-4,4,4-\left[{ }^{2} \mathrm{H}_{3}\right]$-butanoate) and the suitably labelled acetolactate precursor: 1, 2, 3-[ $\left.{ }^{13} \mathrm{C}_{3}\right]-2-\left[{ }^{13} \mathrm{C}^{1} \mathrm{H}_{3}\right]-2-\left[\mathrm{O}^{2} \mathrm{H}\right]-3-\mathrm{oxo}-4,4$, $4-\left[{ }^{2} \mathrm{H}_{3}\right]$-butanoate for the labelling of Leu and valine pro- $S$ methyl groups. No additional peaks were detected neither to the pro- $R$ methyls groups of leucine and valine nor to the isoleucine$\gamma_{2}$ site, confirming the absence of isotopic scrambling. The peaks are splitted in the carbon dimension due to the presence of ${ }^{1} \mathrm{~J}_{\mathrm{CC}}$ coupling as expected from the labelling scheme of the produced samples. 


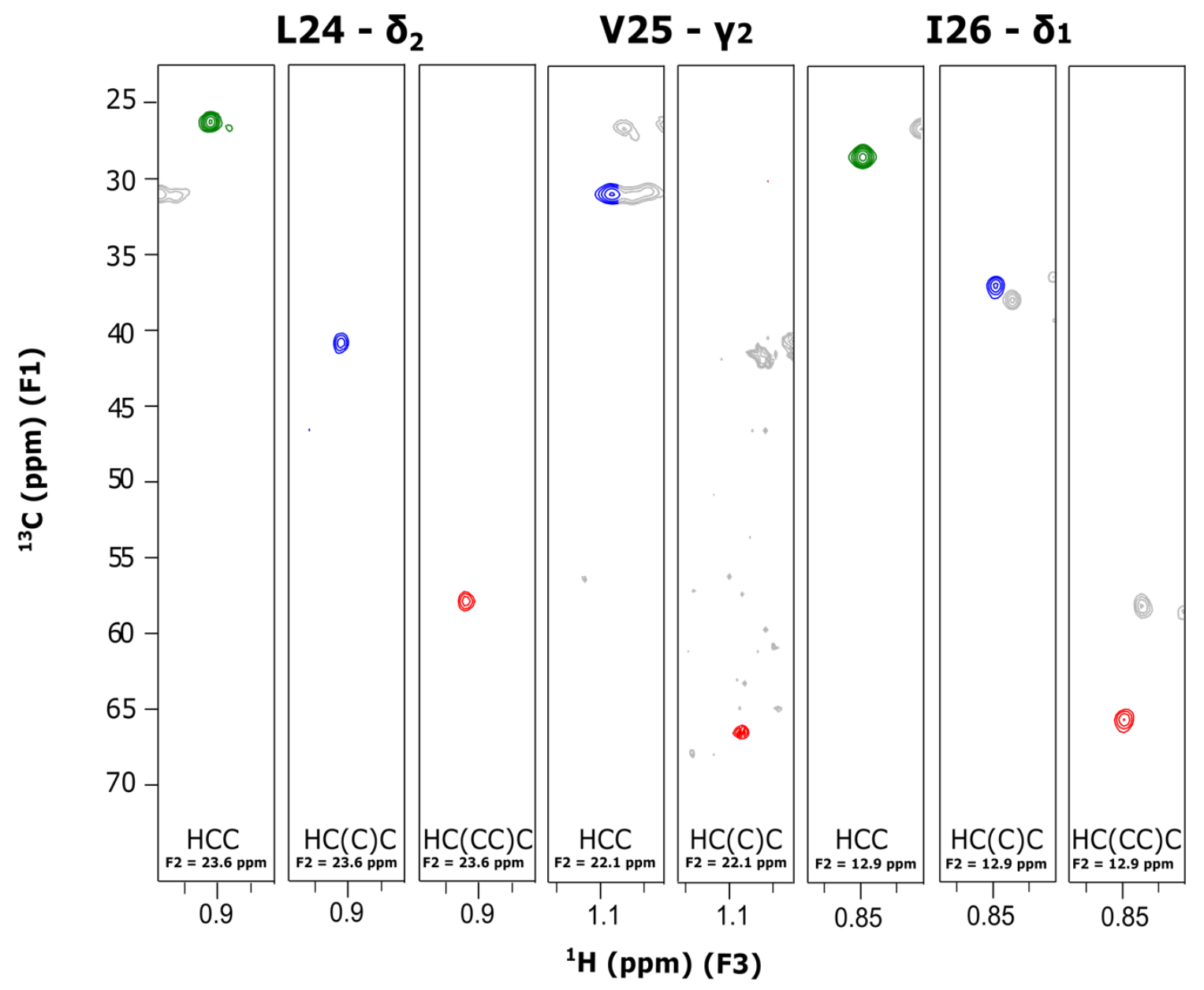

3 Fig. S2 Application to the $87 \mathrm{kDa}$ prefoldin from Pyrococcus horikoshii. Examples of 2D4 extracts from 3D 'out and back' $\mathrm{HCC}, \mathrm{HC}(\mathrm{C}) \mathrm{C}$ and $\mathrm{HC}(\mathrm{CC}) \mathrm{C}$ experiments correlating ${ }^{1} \mathrm{H}\left(\mathrm{F}_{3}\right)$ 5 and ${ }^{13} \mathrm{C}\left(\mathrm{F}_{2}\right)$ methyl resonances with ${ }^{13} \mathrm{C}_{\gamma}$ (green) ${ }^{13} \mathrm{C}_{\beta}$ (blue) or ${ }^{13} \mathrm{C}_{\alpha}$ (red) in $\mathrm{F}_{1}$ dimension of 6 Leu-24, Val-25 and Ile-26 of Pyrococcus horikoshii prefoldin subunit $\beta$. Spectra have been 7 recorded at $310 \mathrm{~K}$ using $0.2 \mathrm{mM} \mathrm{U}-\left[{ }^{2} \mathrm{H},{ }^{15} \mathrm{~N},{ }^{13} \mathrm{C}\right]$, Ile-[2, 3, 4, 4- ${ }^{2} \mathrm{H}_{4} ; 1,2,3,4-{ }^{13} \mathrm{C}_{4}$; $\left.\left.8{ }^{13} \mathrm{C}^{1} \mathrm{H}_{3}\right]^{\delta 1} /\left[{ }^{12} \mathrm{C}^{2} \mathrm{H}_{3}\right]^{\gamma 2}\right]$, Leu- $\left[2,3,3,4-{ }^{2} \mathrm{H}_{4} ; 1,2,3,4-{ }^{13} \mathrm{C}_{4} ;\left[{ }^{13} \mathrm{C}^{1} \mathrm{H}_{3}\right]{ }^{\text {pro- } S} /\left[{ }^{12} \mathrm{C}^{2} \mathrm{H}_{3}\right]{ }^{\text {pro- } R}\right]$, Val- $[2,3-$ $\left.9{ }^{2} \mathrm{H}_{2} ; 1,2,3-{ }^{13} \mathrm{C}_{3} ;\left[{ }^{13} \mathrm{C}^{1} \mathrm{H}_{3}\right]^{\text {pro- } S} /\left[{ }^{12} \mathrm{C}^{2} \mathrm{H}_{3}\right]^{\text {pro- } R}\right]$ sample of prefoldin on an NMR spectrometer operating at a proton frequency of $950 \mathrm{MHz}$. The acquisition parameters were similar to that

11 used for HSP90-NTD, described in Materials and Methods section. Prefoldin was expressed and purified according to the protocol described in Törner et al. (2020) and labelled on the $\beta$

13 subunit only using labelling scheme A, described in Materials and Methods section of the 14 present manuscript. 
1128 - $\mathbf{~} 1$

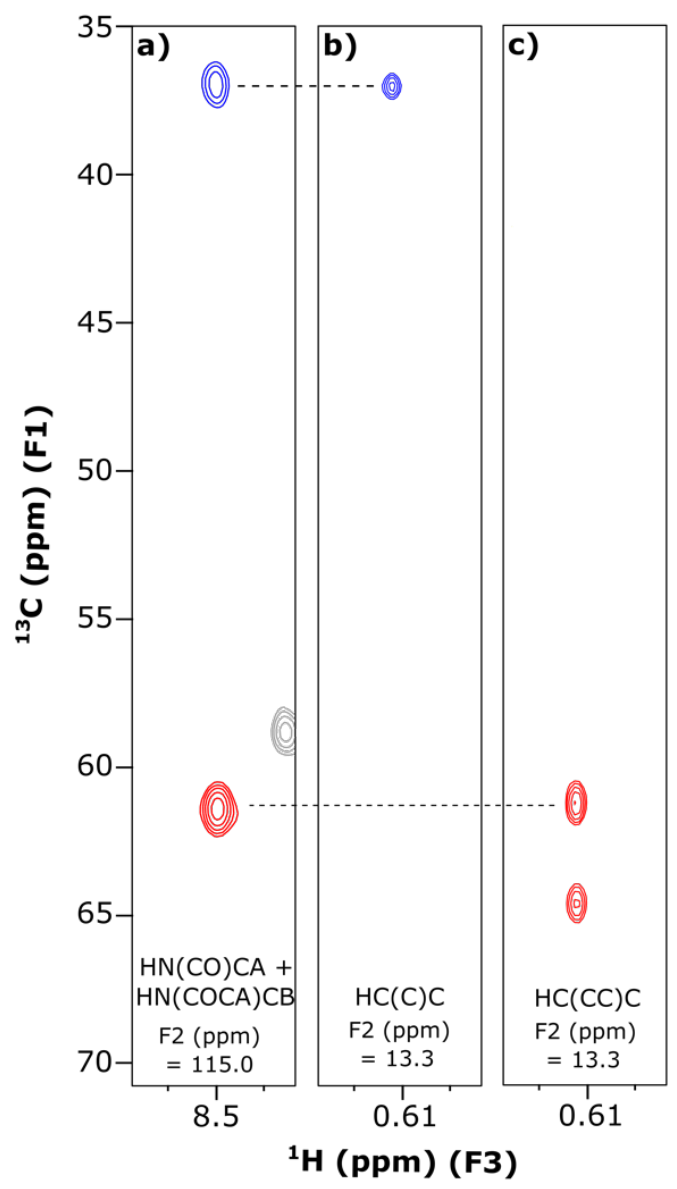

I33 - ठ1

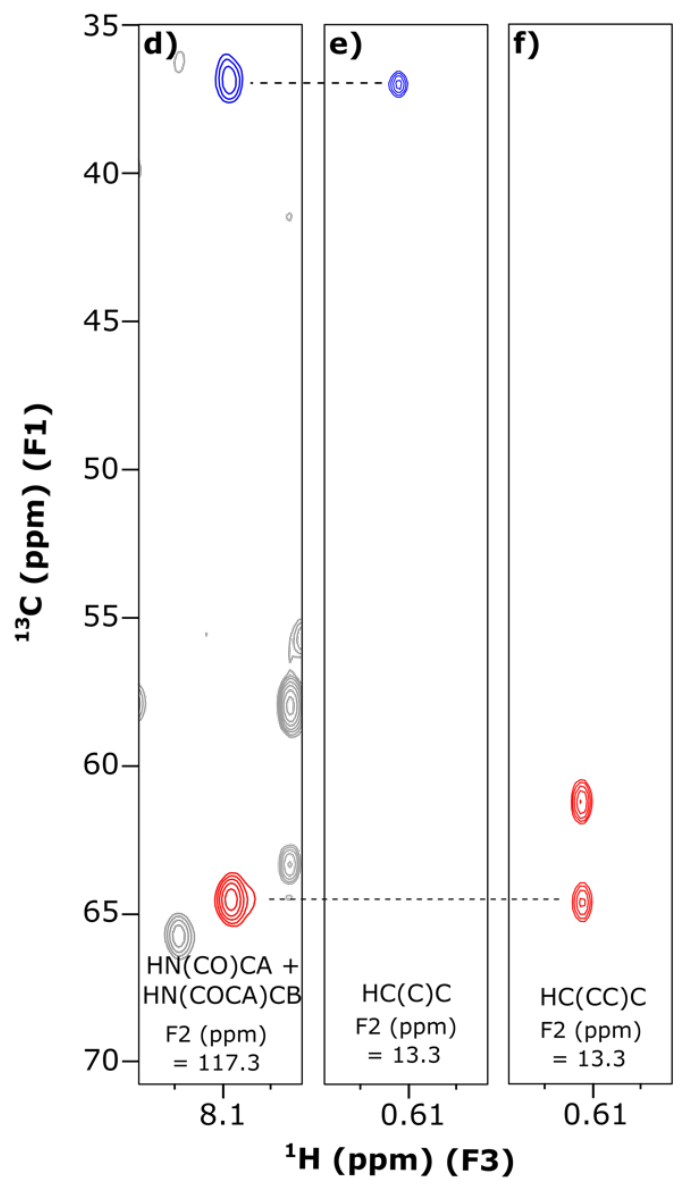

Fig. S3 Assignment transfer from the backbone to the Ile- $\delta_{1}$ methyl groups of Ile-33 and Ile128 of HSP90-NTD. Examples of 2D-extracts from 3D 'out and back' HC(C)C (b and e) and $\mathrm{HC}(\mathrm{CC}) \mathrm{C}$ (c and $\mathrm{f}$ ) experiments correlating ${ }^{1} \mathrm{H}\left(\mathrm{F}_{3}\right)$ and ${ }^{13} \mathrm{C}\left(\mathrm{F}_{2}\right)$ methyl resonances with ${ }^{13} \mathrm{C}_{\beta}$ (blue) or ${ }^{13} \mathrm{C}_{\alpha}$ (red) in $\mathrm{F}_{1}$ dimension. Panels a and d display the corresponding $2 \mathrm{D} \mathrm{HN}(\mathrm{CO}) \mathrm{CA}$ and HN(COCA)CB extracts for Ile-128 (a) and Ile-33 (d) allowing to connect Ile-33- $\delta_{1}$ and Ile$128-\delta_{1}$ methyl groups to previously assigned backbone atoms. 3D spectra were recorded on an 3 NMR spectrometer operating at a proton frequency of $600 \mathrm{MHz}$ using the $\mathrm{U}-\left[{ }^{2} \mathrm{H},{ }^{15} \mathrm{~N},{ }^{13} \mathrm{C}\right]$, Ile$\left.4 \quad\left[2,3,4,4-{ }^{2} \mathrm{H}_{4} ; 1,2,3,4-{ }^{13} \mathrm{C}_{4} ;{ }^{13} \mathrm{C}^{1} \mathrm{H}_{3}\right]{ }^{\delta 1} /\left[{ }^{12} \mathrm{C}^{2} \mathrm{H}_{3}\right]^{\gamma 2}\right]$, Leu- $\left[2,3,3,4-{ }^{2} \mathrm{H}_{4} ; 1,2,3,4-{ }^{13} \mathrm{C}_{4}\right.$; $\left.5 \quad\left[{ }^{13} \mathrm{C}^{1} \mathrm{H}_{3}\right]{ }^{\text {pro- } S} /\left[{ }^{12} \mathrm{C}^{2} \mathrm{H}_{3}\right]{ }^{\text {pro- } R}\right]$, Val- $\left[2,3-{ }^{2} \mathrm{H}_{2} ; 1,2,3-{ }^{13} \mathrm{C}_{3} ;\left[{ }^{13} \mathrm{C}^{1} \mathrm{H}_{3}\right]{ }^{\text {pro- } S} /\left[{ }^{12} \mathrm{C}^{2} \mathrm{H}_{3}\right]{ }^{\text {pro- } R}\right]$ labelled 6 sample or $\mathrm{U}-\left[{ }^{2} \mathrm{H},{ }^{15} \mathrm{~N},{ }^{13} \mathrm{C}\right]$ labelled sample (3D HN(CO)CA and $\left.\mathrm{HN}(\mathrm{COCA}) \mathrm{CB}\right)$. 

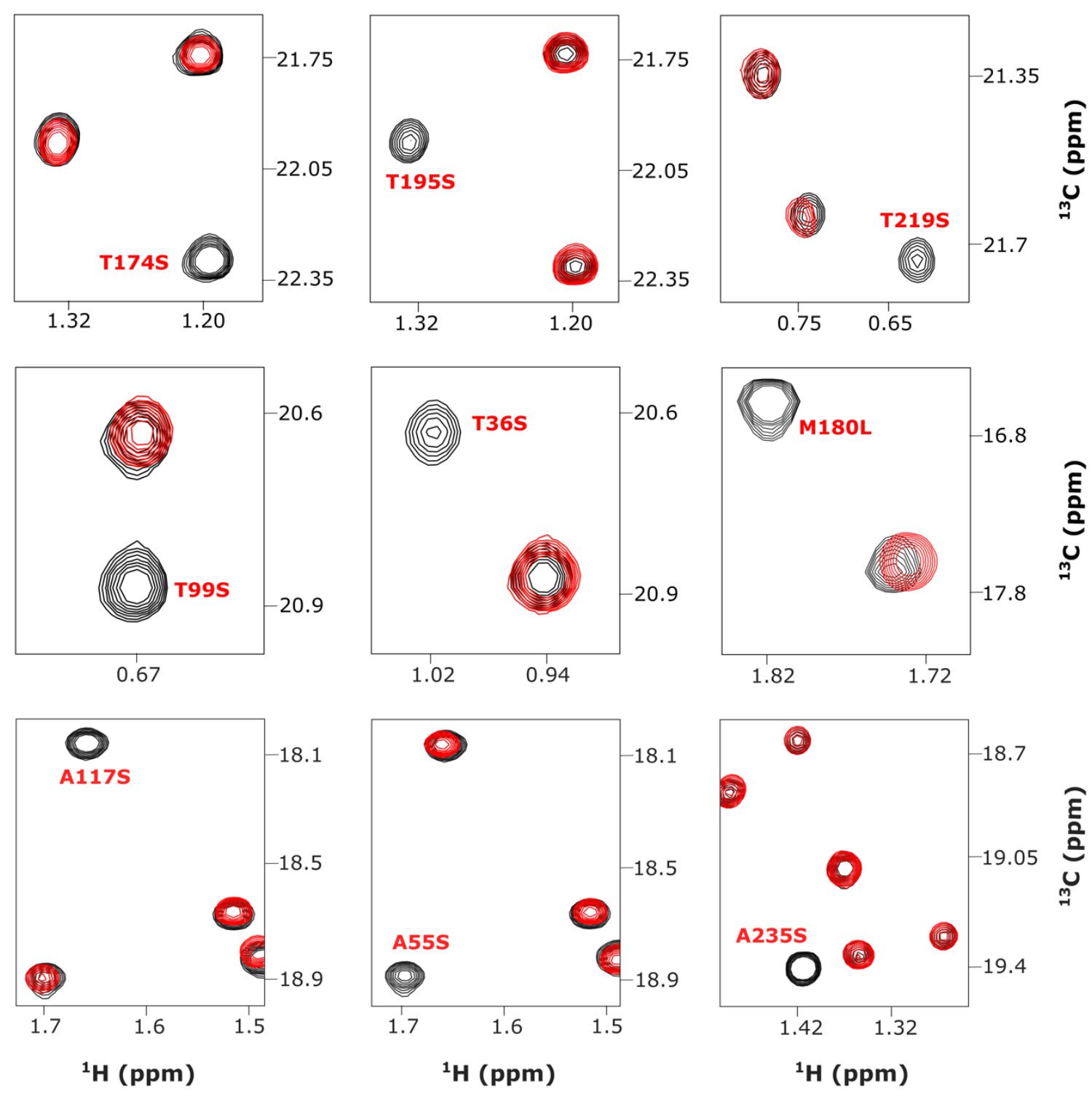

Fig. S4 Assignment of methyl groups using mutagenesis. Examples of $2 \mathrm{D}{ }^{1} \mathrm{H}-{ }^{13} \mathrm{C}$ SOFAST methyl TROSY spectra of HSP90-NTD mutants, for which no or minor chemical shift perturbations are observed. Spectra were acquired on an NMR spectrometer operating at a proton frequency of $850 \mathrm{MHz}$. Each mutant spectrum extract (colored) is superimposed with the corresponding spectra acquired using wild type HSP90-NTD methyl labelled spectra (black). The signal corresponding to each mutant is annotated in color. List of the mutants

10 produced for this study: M12L, M30L M119L, M130L, M180L, A21S, A24S, A27S, A55S, A101S, A111S, A117S, A121S, A124S, A126S, A161S, A166S, A235S, T19S, T36S, T65S, T99S, T109S, T115S, T152S, T171S, T174S, T184S, T195S, T219S, I104V, L107A, I110V. 


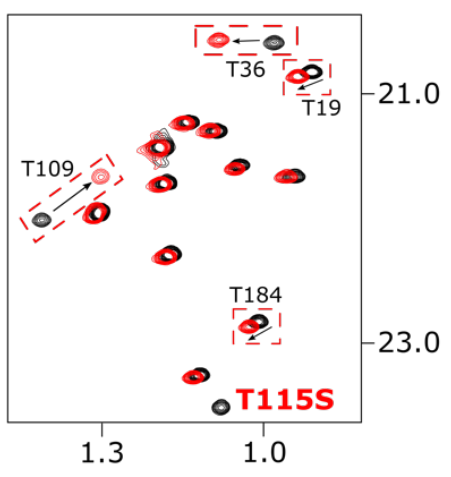

${ }^{1} \mathbf{H}$ (ppm)
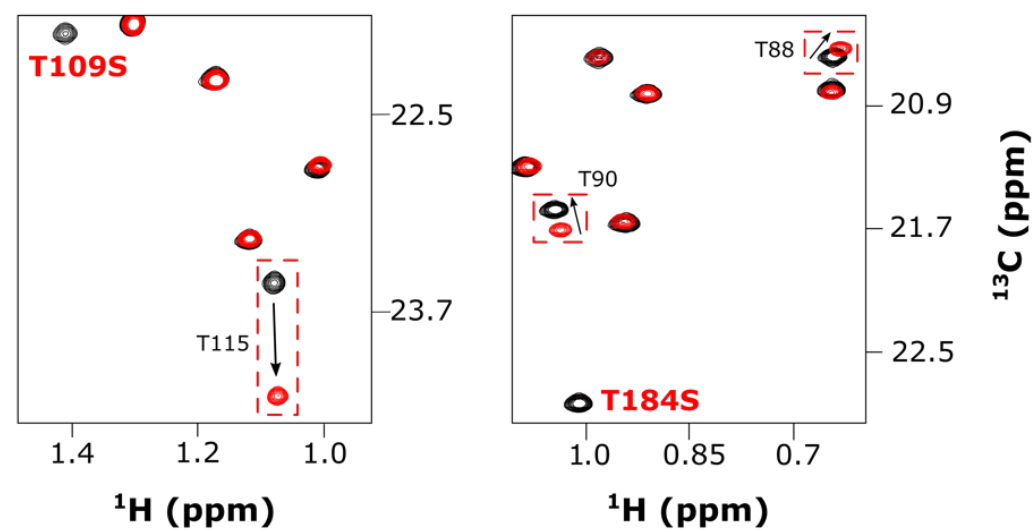

4

5

6 
Table S1: Output file from MAGIC software for the assignment of HSP90-NTD methyl groups.

3

4

5

6

7

8

9

10

11

12

13

14

15

16

17

18

The $1^{\text {st }}$ column displays the best assignment. The $2^{\text {nd }}$ and $3^{\text {rd }}$ columns give the ${ }^{13} \mathrm{C}$ and ${ }^{1} \mathrm{H}$ chemical shifts, respectively. The $4^{\text {th }}$ column represents the sum of all peak-peak connection confident scores for each peak. The $5^{\text {th }}$ column shows the NOE assignment completeness of the strip related to each peak and the $6^{\text {th }}$ column displays the list of all possible assignment with their scores (Monneau et al. 2017).

The automated methyl assignment was performed using the reference structure of HSP90-NTD (PDB: 1YES). MAGIC was run with a score threshold factor of 1, distance thresholds of 7$10 \AA$ and using the 344 inter methyl NOE cross peaks ( $\mathrm{S} / \mathrm{N} \geq 5$ ) detected (Fig. 4e). In addition, MAGIC was given the methyl type for each methyl group, previously identified using specific methyl labelling. In blue are the methyl groups assigned automatically by MAGIC that have 1) a single assignment, 2) a high NOE assignment completeness of the strip related to each peak $(>50 \%)$ and 3$)$ a high total confidence score value $(\geq 7)$.

\begin{tabular}{|c|c|c|c|c|c|c|c|c|}
\hline $\begin{array}{c}\text { Predicted } \\
\text { Assignment }\end{array}$ & $\begin{array}{l}{ }^{13} \mathrm{C} \\
\mathrm{ppm}\end{array}$ & $\begin{array}{c}{ }^{1} \mathbf{H} \\
\mathbf{p p m}\end{array}$ & Score & $\begin{array}{c}\% \\
\text { NOE }\end{array}$ & \multicolumn{2}{|c|}{ Possible Assignment } & & \\
\hline V144CG*-HG* & 15.487 & -0.566 & 31.48 & 0.86 & \{'V144CG': & $215.504\}$ & & \\
\hline L56CD*-HD* & 26.036 & 0.428 & 9.0 & 1.0 & \{'L56CD': & $215.504\}$ & & \\
\hline L89CD*-HD* & 25.59 & 1.159 & 26.22 & 1.0 & \{'L89CD': & $215.504\}$ & & \\
\hline L45CD*-HD* & 25.544 & 0.731 & 36.08 & 1.0 & \{'L80CD': & 207.896 & 'L45CD': & $215.504\}$ \\
\hline L80CD*-HD* & 25.474 & 0.86 & 33.17 & 1.0 & \{'L80CD': & 215.504 & 'L45CD': & $207.896\}$ \\
\hline L198CD*-HD* & 24.747 & 0.717 & 15.0 & 1.0 & \{'L198CD': & $215.504\}$ & & \\
\hline L32CD*-HD* & 24.451 & 0.802 & 13.67 & 0.8 & \{'L32CD': & $215.504\}$ & & \\
\hline L143CD*-HD* & 24.158 & 1.061 & 13.0 & 1.0 & \{'L143CD': & 215.504 & 'L122CD': & $206.867\}$ \\
\hline L76CD*-HD* & 23.647 & 0.605 & 9.0 & 1.0 & \{'L70CD': & 207.413 & 'L76CD': & $215.504\}$ \\
\hline T94CG2-HG2 & 23.292 & 1.157 & 7.0 & 1.0 & $\begin{array}{l}\{\text { 'T184CG2': } \\
\text { 'T94CG2': }\end{array}$ & $\begin{array}{l}206.767 \\
215.504\} \\
\end{array}$ & 'T152CG2': & 207.402 \\
\hline T115CG2-HG2 & 23.566 & 1.118 & 24.6 & 1.0 & \{'T115CG2': & $215.504\}$ & & \\
\hline M130CE-HE & 17.026 & 2.213 & 5.0 & 0.25 & \{'M130CE': & $215.504\}$ & & \\
\hline V207CG*-HG* & 23.223 & 0.91 & 27.69 & 1.0 & \{'V207CG': & $215.504\}$ & & \\
\hline V172CG*-HG* & 23.024 & 1.257 & 3.0 & 0.5 & \{'V172CG': & $215.504\}$ & & \\
\hline L190CD*-HD* & 22.76 & 0.615 & 33.53 & 1.0 & \{'L190CD': & $215.504\}$ & & \\
\hline V148CG*-HG* & 22.646 & 0.178 & 24.0 & 0.83 & \{'V148CG': & $215.504\}$ & & \\
\hline L48CD*-HD* & 22.527 & 0.93 & 19.5 & 0.67 & \{'L48CD': & $215.504\}$ & & \\
\hline T19CG2-HG2 & 22.331 & 1.204 & 2.0 & 0.0 & $\begin{array}{l}\text { \{'T19CG2': } \\
\text { 'T174CG2': }\end{array}$ & $\begin{array}{l}215.504 \\
215.504 \\
\end{array}$ & $\begin{array}{l}\text { 'T176CG2': } \\
\text { 'T171CG2': }\end{array}$ & $\begin{array}{l}215.504 \\
215.504\}\end{array}$ \\
\hline V92CG*-HG* & 22.125 & 0.946 & 27.35 & 1.0 & \{'V92CG': & $215.504\}$ & & \\
\hline L70CD*-HD* & 22.186 & 0.801 & 10.39 & 1.0 & \{'L70CD': & 215.504 & 'L76CD': & $207.413\}$ \\
\hline I214CD1-HD1 & 10.135 & 0.86 & 13.38 & 1.0 & \{'I78CD1': & 207.021 & 'I214CD1': & $215.504\}$ \\
\hline I26CD1-HD1 & 11.564 & 0.908 & 14.0 & 1.0 & \{'I26CD1': & $215.504\}$ & & \\
\hline I110CD1-HD1 & 11.885 & 0.831 & 2.0 & 1.0 & \{'I110CD1': & $215.504\}$ & & \\
\hline I151CD1-HD1 & 12.894 & 0.916 & 15.0 & 0.57 & \{'I151CD1': & $215.504\}$ & & \\
\hline I33CD1-HD1 & 13.355 & 0.661 & 36.6 & 1.0 & \{'I33CD1': & $215.504\}$ & & \\
\hline I203CD1-HD1 & 13.467 & 0.874 & 33.35 & 1.0 & \{'I203CD1': & $215.504\}$ & & \\
\hline I49CD1-HD1 & 13.848 & 0.775 & 34.45 & 0.86 & \{'I49CD1': & $215.504\}$ & & \\
\hline
\end{tabular}




\begin{tabular}{|c|c|c|c|c|c|c|c|c|}
\hline I34CD1-HD1 & 14.091 & 0.859 & 2.0 & 1.0 & $\{$ 'I34CD1': & $215.504\}$ & & \\
\hline I187CD1-HD1 & 14.32 & 0.88 & 12.37 & 1.0 & \{'I187CD1': & $215.504\}$ & & \\
\hline I59CD1-HD1 & 14.25 & 0.89 & 8.37 & 0.75 & \{'I96CD1': & 207.538 & 'I59CD1': & $215.504\}$ \\
\hline I131CD1-HD1 & 14.458 & 0.688 & 23.0 & 0.86 & \{'I131CD1': & $215.504\}$ & & \\
\hline I78CD1-HD1 & 14.622 & 0.779 & 24.0 & 1.0 & $\begin{array}{l}\text { \{'I218CD1': } \\
\text { 'I214CD1': }\end{array}$ & $\begin{array}{l}207.374 \\
207.021\}\end{array}$ & 'I & 15.504 \\
\hline M119CE-HE & 16.667 & 2.047 & 26.67 & 0.71 & \{'M119CE': & $215.504\}$ & & \\
\hline I218CD1-HD1 & 14.66 & 0.916 & 22.0 & 0.8 & $\begin{array}{l}\text { \{'I218CD1': } \\
\text { 'I214CD1': }\end{array}$ & $\begin{array}{l}215.504 \\
206.692\}\end{array}$ & 'I78 & 207.374 \\
\hline I104CD1-HD1 & 14.808 & 0.565 & 4.0 & 1.0 & \{'I104CD1': & $215.504\}$ & & \\
\hline I81CD1-HD1 & 14.949 & 0.733 & 42.89 & 0.45 & \{'I81CD1': & $215.504\}$ & & \\
\hline I43CD1-HD1 & 15.1 & 0.714 & 10.0 & 1.0 & $\{$ 'I43CD1': & 215.504 & 'I128CD1': & $208.077\}$ \\
\hline I96CD1-HD1 & 15.467 & 0.865 & 5.92 & 0.67 & \{'I96CD1': & 215.504 & & $207.538\}$ \\
\hline I206CD1-HD1 & 15.535 & 1.076 & 28.33 & 0.83 & \{'I206CD1': & $215.504\}$ & & \\
\hline I91CD1-HD1 & 16.128 & 0.832 & 77.51 & 0.81 & \{'I91CD1': & $215.504\}$ & & \\
\hline A124CB-HB & 16.617 & 1.357 & 6.0 & 0.67 & $\begin{array}{l}\text { \{'A121CB': } \\
\text { 'A124CB': }\end{array}$ & $\begin{array}{l}215.504 \\
215.504\}\end{array}$ & 'A1 & 207.223 \\
\hline A166CB-HB & 16.771 & 1.262 & 2.0 & 1.0 & \{'A166CB': & $215.504\}$ & & \\
\hline A27CB-HB & 17.326 & 1.486 & 2.0 & 1.0 & \{'A27CB': & 215.504 & 'A2 & 047 \\
\hline V136CG*-HG* & 17.675 & 0.576 & 19.67 & 1.0 & \{'V136CG': & $215.504\}$ & & \\
\hline A101CB-HB & 17.824 & 1.225 & 3.0 & 1.0 & \{'A101CB': & $215.504\}$ & & \\
\hline A141CB-HB & 18.538 & 0.827 & 15.0 & 1.0 & \{'A145CB': & & 'A141CB': & $215.504\}$ \\
\hline A121CB-HB & 18.655 & 1.528 & 4.33 & 1.0 & $\begin{array}{l}\{\mathrm{A} 121 \mathrm{CB} \text { ': } \\
\text { 'A126CB': }\end{array}$ & $\begin{array}{r}215.504 \\
207.223 \\
\end{array}$ & $\begin{array}{l}\text { 'A117CB': } \\
\text { 'A124CB': }\end{array}$ & $\begin{array}{l}207.058 \\
215.504\}\end{array}$ \\
\hline A111CB-HB & 18.69 & 1.429 & 5.0 & 1.0 & $\begin{array}{l}\{\text { 'A111CB': } \\
\text { 'A24CB': }\end{array}$ & $\begin{array}{l}215.504 \\
207.059\}\end{array}$ & 'A27CB': & 207.455 \\
\hline A24CB-HB & 18.812 & 1.5 & 2.0 & 1.0 & \{'A27CB': & 215.504 & 'A24CB': & $215.504\}$ \\
\hline A126CB-HB & 19.272 & 1.272 & 9.83 & 1.0 & \{'A121CB': & 207.223 & & 15.504 \\
\hline M180CE-HE & 16.604 & 1.829 & 29.55 & 0.64 & \{'M180CE': & $215.504\}$ & & \\
\hline T152CG2-HG2 & 19.402 & 1.427 & 3.23 & 0.4 & $\{$ T152CG2': & $215.504\}$ & & \\
\hline V222CG*-HG* & 20.053 & 0.894 & 5.0 & 1.0 & \{'V222CG': & $215.504\}$ & & \\
\hline T36CG2-HG2 & 20.646 & 1.008 & 8.0 & 1.0 & \{'T36CG2': & $215.504\}$ & & \\
\hline T88CG2-HG2 & 20.629 & 0.675 & 8.0 & 0.75 & $\{$ 'T88CG2': & 215.504 & 'T1 & $207.358\}$ \\
\hline T99CG2-HG2 & 20.83 & 0.676 & 2.0 & 0.33 & \{'T99CG2': & $215.504\}$ & & \\
\hline L220CD*-HD* & 26.75 & 0.906 & 12.31 & 1.0 & \{'L220CD': & $215.504\}$ & & \\
\hline V186CG*-HG* & 20.862 & 1.1 & 19.26 & 0.57 & \{'V150CG': & 207.024 & 'V186CG': & $215.504\}$ \\
\hline T176CG2-HG2 & 21.263 & 1.172 & 2.0 & 0.0 & $\begin{array}{l}\{\text { 'T171CG2': } \\
\text { 'T174CG2': }\end{array}$ & $\begin{array}{c}215.504 \\
215.504 \\
\end{array}$ & $\begin{array}{l}\text { 'T176CG2': } \\
\text { 'T19CG2': }\end{array}$ & $\begin{array}{l}215.504 \\
215.504\}\end{array}$ \\
\hline T149CG2-HG2 & 21.331 & 1.498 & 9.0 & 1.0 & \{'T149CG2': & $215.504\}$ & & \\
\hline A145CB-HB & 21.67 & 0.932 & 16.27 & 1.0 & \{'A145CB': & 215.504 & 'A141CB': & $207.062\}$ \\
\hline T90CG2-HG2 & 21.638 & 1.078 & 29.0 & 0.71 & \{'T90CG2': & $215.504\}$ & & \\
\hline T195CG2-HG2 & 21.988 & 1.34 & 5.0 & 1.0 & \{'T195CG2': & 215.504 & 'T88CG2': & $207.358\}$ \\
\hline L188CD*-HD* & 26.645 & 0.575 & 38.1 & 0.78 & \{'L188CD': & $215.504\}$ & & \\
\hline T109CG2-HG2 & 22.02 & 1.444 & 3.0 & 1.0 & \{'T109CG2': & $215.504\}$ & & \\
\hline L122CD*-HD* & 22.419 & 0.431 & 8.1 & 0.75 & \{'L143CD': & 206.867 & 'L122CD': & $215.504\}$ \\
\hline L103CD*-HD* & 24.974 & 0.797 & 2.73 & 1.0 & $\begin{array}{c}\text { \{'L103CD': } \\
\text { 'L64CD': }\end{array}$ & $\begin{array}{l}215.504 \\
207.687\}\end{array}$ & 'L107CD': & 207.733 \\
\hline A161CB-HB & 21.9 & 1.327 & 7.0 & 0.67 & \{'A161CB': & $215.504\}$ & & \\
\hline
\end{tabular}




\begin{tabular}{|c|c|c|c|c|c|c|c|c|}
\hline L29CD*-HD* & 26.252 & 0.89 & 27.0 & 1.0 & \{'L29CD': & $215.504\}$ & & \\
\hline A55CB-HB & 19.402 & 1.427 & 3.23 & 0.0 & $\begin{array}{l}\{\text { 'A24CB': } \\
\text { 'A21CB': } \\
\text { 'A27CB': } \\
\text { 'A235CB': } \\
\text { 'A124CB': }\end{array}$ & $\begin{array}{c}208.147 \\
215.504 \\
208.147 \\
215.504 \\
207.058\} \\
\end{array}$ & $\begin{array}{l}\text { 'A166CB': } \\
\text { 'A111CB': } \\
\text { 'A117CB': } \\
\text { 'A55CB': }\end{array}$ & $\begin{array}{c}208.147 \\
207.455 \\
215.504 \\
215.504\end{array}$ \\
\hline T65CG2-HG2 & 20.867 & 0.944 & 2.0 & 0.0 & $\begin{array}{l}\{\text { 'T171CG2': } \\
\text { 'T174CG2': } \\
\text { 'T19CG2': }\end{array}$ & $\begin{array}{c}215.504 \\
215.504 \\
215.504\end{array}$ & $\begin{array}{l}\text { 'T176CG2': } \\
\text { 'T65CG2': } \\
\text { 'T219CG2': }\end{array}$ & $\begin{array}{c}215.504 \\
215.504 \\
215.504\}\end{array}$ \\
\hline T184CG2-HG2 & 21.357 & 1.117 & 2.0 & 1.0 & $\begin{array}{l}\{\text { T171CG2': } \\
\text { 'T94CG2': } \\
\text { 'T174CG2': } \\
\text { 'T19CG2': } \\
\text { 'T184CG2': }\end{array}$ & $\begin{array}{c}207.047 \\
206.547 \\
207.047 \\
207.047 \\
215.504\} \\
\end{array}$ & $\begin{array}{l}\text { 'T152CG2': } \\
\text { 'T176CG2': } \\
\text { 'T65CG2': } \\
\text { 'T219CG2': }\end{array}$ & $\begin{array}{c}207.267 \\
207.047 \\
207.047 \\
207.047\end{array}$ \\
\hline T219CG2-HG2 & 21.756 & 1.216 & 3.0 & 0.0 & $\begin{array}{c}\{\text { T171CG2': } \\
\text { 'T94CG2': } \\
\text { 'T174CG2': } \\
\text { 'T19CG2': } \\
\text { 'T184CG2': }\end{array}$ & $\begin{array}{c}215.504 \\
207.402 \\
215.504 \\
215.504 \\
207.267\} \\
\end{array}$ & $\begin{array}{l}\text { 'T152CG2': } \\
\text { 'T176CG2': } \\
\text { 'T65CG2': } \\
\text { 'T219CG2': }\end{array}$ & $\begin{array}{c}208.147 \\
215.504 \\
215.504 \\
215.504\end{array}$ \\
\hline
\end{tabular}

2

\begin{tabular}{|c|c|c|lll|}
\hline $\begin{array}{c}\text { Not } \\
\text { Assigned }\end{array}$ & $\begin{array}{c}\mathbf{1}^{\mathbf{1 3}} \mathbf{C} \\
\mathbf{p p m}\end{array}$ & $\begin{array}{c}\mathbf{1} \mathbf{H} \\
\mathbf{p p m}\end{array}$ & & \\
\hline 3 & 16.949 & 2.087 & NotAss ['M30CE' & 'M98CE' & 'M12CE'] \\
\hline 5 & 17.58 & 1.732 & NotAss ['M30CE' & 'M98CE' & 'M12CE'] \\
\hline 49 & 16.898 & 1.43 & NotAss ['M30CE' & 'M98CE' & 'M12CE'] \\
\hline 53 & 18.034 & 1.659 & NotAss ['A21CB' & 'A117CB' & 'A235CB'] \\
\hline 58 & 18.938 & 1.694 & NotAss ['A21CB' & 'A117CB' & 'A235CB'] \\
\hline 60 & 19.325 & 1.362 & NotAss ['A21CB' & 'A117CB' & 'A235CB'] \\
\hline 64 & 20.266 & 0.959 & NotAss ['V17CG' & 'V150CG' & 'V230CG'] \\
\hline 67 & 20.699 & 0.9 & NotAss ['V17CG' & 'V150CG' & 'V230CG'] \\
\hline 73 & 21.392 & -0.838 & NotAss ['L64CD' & 'L107CD'] & \\
\hline 75 & 21.709 & 0.974 & NotAss ['T171CG2' & 'T174CG2'] & \\
\hline 80 & 21.965 & 0.865 & NotAss ['L64CD' & 'L107CD'] & \\
\hline 82 & 22.208 & 0.844 & NotAss ['V17CG' & 'V150CG' & 'V230CG'] \\
\hline 86 & 22.86 & 1.022 & NotAss ['T171CG2' & 'T174CG2'] & \\
\hline
\end{tabular}


Table S2: Assignment of HSP90-NTD methyl groups

3

4

\begin{tabular}{|c|c|c|}
\hline Met & $\mathbf{H}(\boldsymbol{\varepsilon})$ & $\mathbf{C}(\boldsymbol{\varepsilon})$ \\
\hline M12 & 2.117 & 16.889 \\
\hline M30 & 1.426 & 16.886 \\
\hline M98 & 1.741 & 17.594 \\
\hline M119 & 2.035 & 16.644 \\
\hline M130 & 2.210 & 17.000 \\
\hline M180 & 1.818 & 16.593 \\
\hline
\end{tabular}

\begin{tabular}{|c|c|c|}
\hline Thr & $\mathbf{H}(\boldsymbol{\gamma} \mathbf{2})$ & $\mathbf{C}(\boldsymbol{\gamma} \mathbf{2})$ \\
\hline T19 & 0.942 & 20.832 \\
\hline T36 & 1.002 & 20.622 \\
\hline T65 & 1.205 & 21.746 \\
\hline T88 & 0.664 & 20.605 \\
\hline T90 & 1.07 & 21.611 \\
\hline T94 & 1.144 & 23.293 \\
\hline T99 & 0.667 & 20.819 \\
\hline T109 & 1.437 & 22.033 \\
\hline T115 & 1.104 & 23.567 \\
\hline T149 & 1.492 & 21.304 \\
\hline T152 & 1.430 & 19.470 \\
\hline T171 & 1.111 & 21.333 \\
\hline T174 & 1.199 & 22.314 \\
\hline T176 & 1.169 & 21.250 \\
\hline T184 & 1.036 & 22.863 \\
\hline T195 & 1.326 & 21.960 \\
\hline T219 & 0.973 & 21.686 \\
\hline
\end{tabular}

\section{5}

\begin{tabular}{|c|c|c|}
\hline Ala & $\mathbf{H}(\boldsymbol{\beta})$ & $\mathbf{C}(\boldsymbol{\beta})$ \\
\hline A21 & 1.356 & 19.310 \\
\hline A24 & 1.489 & 18.799 \\
\hline A27 & 1.476 & 17.297 \\
\hline A55 & 1.696 & 18.870 \\
\hline A101 & 1.211 & 17.806 \\
\hline A111 & 1.419 & 18.635 \\
\hline A117 & 1.654 & 18.031 \\
\hline A121 & 1.353 & 16.570 \\
\hline A124 & 1.514 & 18.640 \\
\hline A126 & 1.265 & 19.266 \\
\hline A141 & 0.819 & 18.528 \\
\hline A145 & 0.917 & 21.654 \\
\hline A161 & 1.318 & 21.910 \\
\hline A166 & 1.257 & 16.777 \\
\hline A235 & 1.415 & 19.384 \\
\hline
\end{tabular}




\begin{tabular}{|c|c|c|}
\hline Ile & $\mathbf{H}(\boldsymbol{\delta} \mathbf{1})$ & $\mathbf{C}(\boldsymbol{\delta} \mathbf{1})$ \\
\hline $\mathrm{I} 26^{\mathrm{b}}$ & 0.899 & 11.547 \\
\hline $\mathrm{I} 33 / \mathrm{I} 128^{\mathrm{a}}$ & 0.647 & 13.317 \\
\hline${\mathrm{I} 34^{\mathrm{a}}}^{\mathrm{a}}$ & 0.842 & 14.078 \\
\hline $\mathrm{I} 43^{\mathrm{a}}$ & 0.702 & 15.097 \\
\hline $\mathrm{I} 49^{\mathrm{a}}$ & 0.765 & 13.830 \\
\hline $\mathrm{I}^{\mathrm{a}}{ }^{\mathrm{a}}$ & 0.876 & 14.287 \\
\hline $\mathrm{I} 78^{\mathrm{a}}$ & 0.771 & 14.631 \\
\hline $\mathrm{I} 81^{\mathrm{a}}$ & 0.729 & 14.935 \\
\hline $\mathrm{I} 91^{\mathrm{a}}$ & 0.818 & 16.139 \\
\hline $\mathrm{I} 96^{\mathrm{a}}$ & 0.850 & 15.440 \\
\hline $\mathrm{I} 104^{\mathrm{a}}$ & 0.585 & 14.778 \\
\hline $\mathrm{I} 110^{\mathrm{b}}$ & 0.821 & 11.783 \\
\hline $\mathrm{I} 131^{\mathrm{a}}$ & 0.675 & 14.498 \\
\hline $\mathrm{I} 151^{\mathrm{a}}$ & 0.910 & 12.853 \\
\hline $\mathrm{I} 187^{\mathrm{a}}$ & 0.876 & 14.287 \\
\hline $\mathrm{I} 203^{\mathrm{a}}$ & 0.861 & 13.455 \\
\hline $\mathrm{I} 206^{\mathrm{a}}$ & 1.069 & 15.528 \\
\hline $\mathrm{I} 214^{\mathrm{a}}$ & 0.853 & 10.015 \\
\hline $\mathrm{I} 218^{\mathrm{a}}$ & 0.909 & 14.670 \\
\hline
\end{tabular}

\begin{tabular}{|c|c|c|}
\hline Leu & $\mathbf{H}(\boldsymbol{\delta} 2)$ & $\mathbf{C}(\boldsymbol{\delta} 2)$ \\
\hline $\mathrm{L} 29^{\mathrm{c}}$ & 0.876 & 26.240 \\
\hline $\mathrm{L} 32^{\mathrm{c}}$ & 0.786 & 24.429 \\
\hline $\mathrm{L} 45^{\mathrm{d}}$ & 0.719 & 25.537 \\
\hline $\mathrm{L} 48^{\mathrm{c}}$ & 0.918 & 22.526 \\
\hline $\mathrm{L}^{2} 6^{\mathrm{c}}$ & 0.411 & 26.037 \\
\hline $\mathrm{L} 64^{\mathrm{c}}$ & 0.853 & 21.951 \\
\hline $\mathrm{L}_{7} 0^{\mathrm{c}}$ & 0.787 & 22.168 \\
\hline${\mathrm{L} 76^{\mathrm{c}}}^{\circ}$ & 0.594 & 23.642 \\
\hline $\mathrm{L}^{2} 0^{\mathrm{c}}$ & 0.846 & 25.472 \\
\hline${\mathrm{L} 89^{\mathrm{c}}}^{\mathrm{c}}$ & 1.149 & 25.579 \\
\hline $\mathrm{L}^{103^{\mathrm{c}}}$ & 0.798 & 25.037 \\
\hline $\mathrm{L} 107^{\mathrm{d}}$ & -0.851 & 21.374 \\
\hline $\mathrm{L} 122^{\mathrm{c}}$ & 0.411 & 22.329 \\
\hline $\mathrm{L} 143^{\mathrm{d}}$ & 1.056 & 24.148 \\
\hline $\mathrm{L}^{188^{\mathrm{d}}}$ & 0.565 & 26.652 \\
\hline $\mathrm{L}^{190^{\mathrm{c}}}$ & 0.601 & 22.739 \\
\hline $\mathrm{L}^{198^{\mathrm{c}}}$ & 0.702 & 24.73 \\
\hline $\mathrm{L} 220^{\mathrm{c}}$ & 0.898 & 26.742 \\
\hline
\end{tabular}

\begin{tabular}{|c|c|c|}
\hline Val & $\mathbf{H}(\boldsymbol{\gamma} \mathbf{2})$ & $\mathbf{C}(\boldsymbol{\gamma} \mathbf{})$ \\
\hline $\mathrm{V} 17^{\mathrm{d}}$ & 0.892 & 20.658 \\
\hline $\mathrm{V} 92^{\mathrm{c}}$ & 0.936 & 22.102 \\
\hline $\mathrm{V} 136^{\mathrm{c}}$ & 0.570 & 17.586 \\
\hline $\mathrm{V} 144^{\mathrm{c}}$ & -0.582 & 15.446 \\
\hline
\end{tabular}




\begin{tabular}{|c|c|c|}
$\mathrm{V} 148^{\mathrm{c}}$ & 0.168 & 22.630 \\
\hline $\mathrm{V} 150^{\mathrm{c}}$ & 0.839 & 22.084 \\
\hline${\mathrm{V} 172^{\mathrm{c}}}^{\mathrm{c}}$ & 1.251 & 23.028 \\
\hline${\mathrm{V} 186^{\mathrm{c}}}^{\mathrm{c}}$ & 1.085 & 20.870 \\
\hline $\mathrm{V} 207^{\mathrm{c}}$ & 0.899 & 23.183 \\
\hline $\mathrm{V} 222^{\mathrm{c}}$ & 0.884 & 20.037 \\
\hline $\mathrm{V} 230$ & 0.949 & 20.244 \\
\hline
\end{tabular}

1

2

3

$4 \quad{ }^{a}$ Residues assigned by (Park et al. 2011) and confirmed by this study.

$5{ }^{\mathrm{b}}$ Assignment was inverted for these two residues in our study compared to (Park et al. 2011).

$6 \quad{ }^{\mathrm{c}}$ Residues stereospecifically assigned by (Lescanne et al. 2018) and confirmed by this study.

$7{ }^{\mathrm{d}}$ Stereospecific assignment was inverted compared to (Lescanne et al. 2018). 